
IMPACT OF LOCATION ON ENVIRONMENTALLY RESPONSIBLE BEHAVIOUR

by

Sylvie Suzanne Marie Godin, Honors BA, York University, 2004

\author{
A Major Research Paper \\ presented to Ryerson University \\ in partial fulfillment of the requirements for the degree of \\ Master of Arts \\ in the Program of \\ Early Childhood Studies
}

Toronto, Ontario, Canada, 2007

(C) Sylvie Suzanne Marie Godin 2007

PROPERTY OF 
UMI Number: EC53592

\section{INFORMATION TO USERS}

The quality of this reproduction is dependent upon the quality of the copy submitted. Broken or indistinct print, colored or poor quality illustrations and photographs, print bleed-through, substandard margins, and improper alignment can adversely affect reproduction.

In the unlikely event that the author did not send a complete manuscript and there are missing pages, these will be noted. Also, if unauthorized copyright material had to be removed, a note will indicate the deletion.

\section{$\mathrm{UMI}^{\circ}$}

UMI Microform EC53592

Copyright 2009 by ProQuest LLC

All rights reserved. This microform edition is protected against unauthorized copying under Title 17, United States Code.

ProQuest LLC

789 East Eisenhower Parkway

P.O. Box 1346

Ann Arbor, MI 48106-1346 


\title{
URBAN AND RURAL CHILDREN AS ENVIRONMENTAL ADVOCATES: THE IMPACT OF LOCATION ON ENVIRONMENTALLY RESPONSIBLE BEHAVIOUR
}

\author{
(C) Sylvie Suzanne Marie Godin, 2007 \\ Master of Arts \\ Early Childhood Studies \\ Ryerson University
}

\begin{abstract}
This research paper is a qualitative study of how urban and rural children (6-8years) experience the natural environment. The literature exploring how place of residence can influence environmental awareness and pro-environmental behaviour among children has been contradictory. This study attempted to explore this question in order to establish any differences between the two sample groups. Semi-structured interviews and drawing analyses were used to examine the children's view of the natural environment and their knowledge of environmentally responsible behaviours. The results indicate that the urban children were more knowledgeable of environmentally responsible behaviours and displayed higher levels of environmental advocacy. These findings support the use of area-specific environmental teaching strategies that may serve to promote environmental awareness and advocacy among children residing in any location.
\end{abstract}

Key words: Children; Environmental advocacy; Environmentally responsible behaviour; Natural environment; Rural and urban environments.

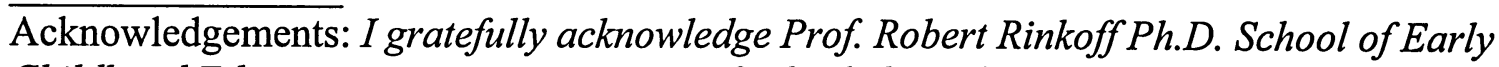
Childhood Education, Ryerson University, for his help and guidance throughout the research and writing process. I would also like to thank my friends and loved ones for all of their continuous support during this strenuous time in my academic career. Lastly, I would like to express gratitude to all those at Ryerson University who have assisted in some way to the success and completion of this major research paper. 


\section{$\underline{\text { Table of Contents }}$}

INTRODUCTION-1

THE NATURAL ENVIRONMENT: THROUGH CHILDREN'S EYES -----.--.--.----5

BARRIERS TO ENVIRONMENTALLY RESPONSIBLE BEHAVIOUR -----------11

URBAN VS RURAL ENVIRONMENTS -

ENVIRONMENTAL EDUCATION --_-_-

IMPLICATIONS OF THE LITERATURE FOR THIS STUDY -

RESEARCHER SELF-DISCLOSURE--

SCOPE AND FOCUS -

SETTING AND SAMPLE -

DATA COLLECTION PROCEDURES -

DATA RECORDING AND ORGANIZATION -

DATA ANALYSIS AND INTERPRETATION

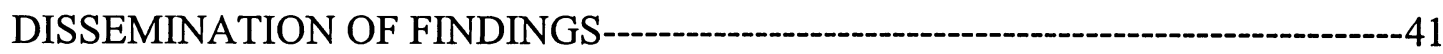

RESULTS - -

Urban Sample ---

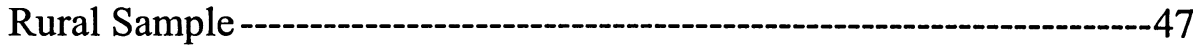

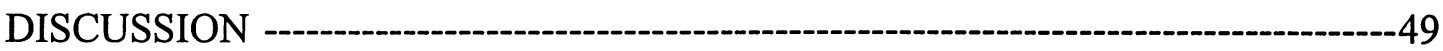

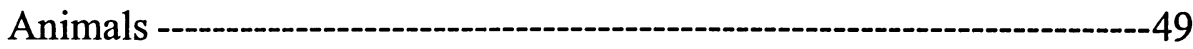

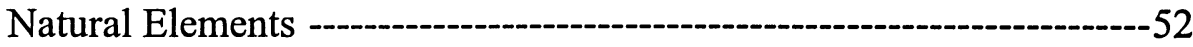

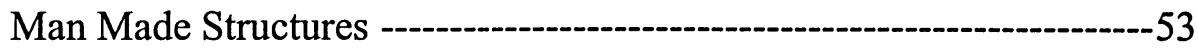

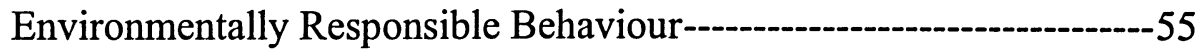

CONCLUSION --10

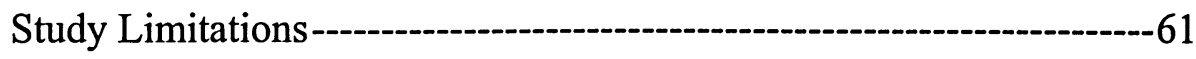

REFERENCES -- 


\section{List of Tables}

TABLE 1: Age and Gender for Both Samples--

\section{$\underline{\text { List of Appendices }}$}

APPENDIX A: Consent Form --

APPENDIX B: Drawings from the Rural Children ---_-

APPENDIX C: Drawings from the Urban Children ---_-

APPENDIX D: Interview Transcript from the Rural Children -------------------75

APPENDIX E: Interview Transcript from the Urban Children -------------83 


\section{Introduction}

Children hold unique views of their natural environment (Cohen, 1994; Hyun, 2005). These views are unique because children see the natural environment through primary perceptions, which are based on sensory-directed experiences (Hyun, 2005). These perceptions, the interactions between the child and the environment, are called bondings-to-the-earth. "This bonding-to-the-earth is an affinity that children across all cultures have for their natural environment that is different from most adults' sense of nature" (Hyun, 2005, p.200). In view of the fact that children see the natural environment differently, the study of childhood conceptions of the environment should seek to uncover their experiences and specifically look at what they mean to them.

The types of environments that children encounter vary depending on the area in which they live (Moore, 1985; van Velsor \& Nilon, 2006). Children residing in the city may not be exposed to forests and wildlife on a regular basis, whereas a child living in the country may very well have access to these in his/her own backyard. The variety of natural environments available to children impacts how they perceive them (Cohen, 1994; Kruse \& Card, 2004; Lindemann-Matthies, 2005) and it is important to look at how specific experiences of the natural environment shape environmentally responsible behaviour.

In this study, I will be examining how children who live in both an urban and a rural setting view their natural environment and how their experiences of the natural environment influence their sense of responsibility towards its protection. As a social constructivist, I feel that children construct their own concept of the state of the natural environment based on what is around them and that this information can be used by 
researchers to help them understand how the children perceive the natural environment. The fact that human activity has damaged the natural environment is no secret (Frantz, Mayer, Norton, \& Rock, 2005) and a change of behaviour is necessary if we are to live in a sustainable society (Mayer \& Frantz, 2004).

In response to today's environmental challenges, the United Nations has attempted to coordinated international action by establishing a more consistent system of international environmental governance. (United Nations Environmental Program, UNEP, 2007). The UNEP provides technical guidelines and resources for governments, policy-makers, civil society, and the public at large. The Kyoto Protocol is but one example of the many world wide efforts to maintain a sustainable environment. Adopted in 1997, and put into action in 2005, the Kyoto Protocol asks all the countries involved, to make an effort towards reducing greenhouse gas emissions (UNFCCC, 2005).

The UNEP has also developed a program designed to help children around the world learn about the protection of the environment and how to act for a better world (http://www.unep.org/tunza/children/.) On a local level, both the Toronto District School Board and the Toronto Catholic District School Board are providing leadership and direction for the protection and conservation of the environment through several programs that engage staff, students and the community in taking action to help build a

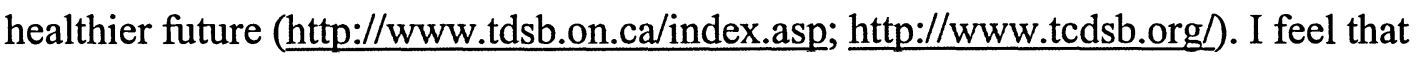
children are important participants in the preservation of the natural environment and only by learning how they experience it will we be able to teach them to protect it.

My research questions are related to the issues of urban and rural children and their views of the natural environment. Do urban and rural children differ in their views 
of the natural environment? What do children in both settings know about the preservation of the natural environment? I have decided to study these populations with the hope that I can establish some common themes between them and see whether there is a difference in the way they perceive the natural environment. I believe that if there is a difference, location specific means of teaching children about the protection of the environment may be required.

In order to grasp the concepts that will be discussed in this study, a few definitions are needed. I have identified these terms and their definitions in order to ensure the consistency of their use throughout this research. The natural environment is considered to be all that is natural or biological in the environment (i.e.: animal, vegetable, and mineral). It is "Of, relating to, or concerning nature: a natural environment (American Heritage Dictionary, 2006)." These elements are at risk of degradation due to environmental stressors such as pollution, erosion, and deforestation. Environmentally responsible behaviour is defined as all actions directed at preserving the state of the natural environment (i.e.: environmental activism, recycling, cleaning public spaces, conserving energy in the home, caring for animals and plants etc...). These actions are motivated by a sense of responsibility. An individual who is responsible is said to be able to make moral or rational decisions on their own, and therefore are answerable for their behaviour (American Heritage Dictionary, 2006). Advocacy is "the action of advocating, pleading for, or supporting a cause or proposal" (Merriam-Webster's Dictionary of Law, 1996). In the context of this research, advocacy refers to the promotion of environmental causes (i.e., conservation efforts, active demonstration etc...). 
The word urban is used to identify environments that relate to, or belong to the city or town (Webster's Encyclopedic Dictionary, 1988). In this case, the urban environment in question is the city of Toronto, Ontario, Canada. The word rural relates to, or is characteristic of the country, or of those living in the country (Webster's Encyclopedic Dictionary, 1988). For the purpose of this study, the rural environment will be represented by the town of Georgetown, Ontario, Canada. Individuals who live in either of these settings have been distinguished in order to observe the specific experiences of children living in these environments. 


\section{The Natural Environment: Through Children's Eyes}

Howe, Khan, and Friedman (1996) state that developmental psychology has neglected to seek understanding of human relationships with nature. This lack of attention is surprising given that it has been shown that, when asked about naturalistic social play activities, children prefer outdoor settings and generally favour areas predominated by nature (Evens, 2006). As of late, there have been more studies focussed on the development of pro-environmental attitudes and awareness among children. However, I believe that there is still a need to understand how these attitudes are shaped by location or place of residence.

Empathy and compassion for the natural environment are major contributors to the development of pro-environmental attitudes (Berenguer, 2007; Lindemann-Matthies, 2005; Mayer \& Frantz, 2004). In a study of the environmental behaviours of adolescents, Meinhold \& Malkus (2005) examined the association between their environmental behaviours, attitudes, self-efficacy and knowledge. They hypothesized that higher levels of pro-environmental attitudes would likely elicit more pro-environmental behaviours among the participants. Their second hypothesis was that the relationship between proenvironmental attitudes and behaviours would be stronger among participants with high self-efficacy. Meinhold and Malkus (2005), define self-efficacy as the confidence that an individual has in their ability to plan and implement a course of action that will lead to accomplishing a task, or to resolve a problem. Their third and last hypothesis was that participants with more environmental knowledge would behave in more proenvironmental ways. 
The results from this study supported their first and third hypotheses in that, when participants displayed higher levels of pro-environmental attitudes, this predicted proenvironmental behaviours and that environmental knowledge influenced proenvironmental behaviour. The second hypothesis was not entirely supported due to a lack of significant evidence of self-efficacy as a moderator for pro-environmental attitudes when predicting behaviour. However, high levels of perceived self-efficacy were positively associated with pro-environmental behaviour.

Although these findings are significant, there were some limitations in the methodology used by Meinhold and Malkus (2005). The measure used to determine the participants' level of pro-environmental behaviour was self reported and was not designed to measure their actual behaviours, which could have lead to distorted results. Also, the participants attended high academically achieving schools and were considered to be of high socio-economic status. Their socio-economic status could have also potentially influenced the results in that they may have had more access to natural settings due to family trips and outings. One positive criticism is that the authors collected their sample from three large cities on the West coast of the U.S. They selected these locations in order to allow for a more diverse population since these cities are inhabited by several different ethnic populations. Even with such a large and diverse sample (848 students), these findings cannot be universally applied to all adolescents. However, they are still relevant to this research. In studying adolescent and adult attitudes, we can see how early development and experiences can lead to a positive or negative attitude towards the natural environment later in life. 
When studying the moral reasoning involved in environmentally responsible attitudes and behaviours, it is important to consider that there are many factors involved. Age, culture, and past experiences are all elements that can influence the moral reasoning behind our actions. Our personal sense of permanence within our environment begins to solidify as we grow older. We tend to become progressively more self-aware of how we interact with our environment as we gain more life experience and these experiences have an impact on the development of environmental views (Palmer, Suggate, Robottom \& Hart, 1999). Kahn and Lourenço (2002) studied children in Portugal and found that awareness of the consequences of not "living in harmony with nature" increased with age among their participants, although their perceived ability to protect the environment did not. Socio-cultural influences can also shape perceptions of the natural environment. Hyun (2005) suggests that the human brain changes physiologically as a result of environmental conditions and this evolution has equipped us with an "ecological brain" that is dependent on socio-cultural environmental input. That is, our cognitive structures are determined by our environmental experiences. Hyun claims that children acquire a "love of nature" early in their development and that this directly affects the cognitive activities of the child's mind. These cognitive activities ultimately shape the way that the natural environment is perceived by the child. "There are inherent aspects of nature itself that help give rise to children's environmental constructions. If so, nature is not a mere cultural convention or artifact, but part of a reality that bounds children's cognition" (Hyun, 2005, p. 201). The way children see the natural environment is influenced by the types of interactions they have had with it in the past. Negative experiences in the natural environment during early childhood have the potential to produce negative effects on 
their future environmental advocacy (Hyun, 2005). These findings demonstrate the importance of promoting positive environmental experiences early in life.

Expressed interest in one's own roots can be positively related to place attachment and this in turn can predict the individual's willingness to engage in pro-social behaviours such as civic-activity (Lewicka, 2005). Place attachment is described by Lewicka as contributing to the formation and preservation of the identity of a person, group or culture and plays a role in promoting self-worth and self-pride. Attachment to the community where we live encourages us to act in its best interest. In a study done by Kearney (2006), it was found that while physical proximity (i.e., green spaces available in the immediate vicinity) to natural areas did not have a powerful effect on neighbourhood satisfaction and place attachment, visual proximity (i.e., green spaces visible from home window) did have an effect. Other research endeavours in this area have recognized that when an individual is bonded, or emotionally attached to a natural setting, they will be more likely to identify problematic conditions within it, as well as be more inclined to participate in it's preservation (Kyle, Graefe, Manning, \& Bacon, 2004; Kyle, Mowen, \& Tarrant, 2004). These findings relate to environmentally responsible behaviour in that the positive feelings that individuals experience for their place of residence and surroundings will lead them to be more motivated to behave in positive ways towards their natural environment. These concepts also relate to the theory of planned behaviour.

This theory suggests that behaviour can be determined by attitudinal factors and perceived behavioural control (Knussen, Yule, MacKenzie, \& Wells, 2004). Conscious reasoning is involved in the development of intentions to carry out certain behaviours and 
the theory of planned behaviour proposes that these actions are under the control of the individual (Knussen, Yule, MacKenzie, \& Wells, 2004).

Kahn Jr. and Friedman have made major contributions to the study of how children understand their natural environment. In a study done in 1995, Kahn and Friedman conceptualized two ways that children can view their natural environments. Homocentric thought views the importance of protecting the environment as a means of self-preservation, and biocentric thought views nature as having intrinsic value and rights. In this study, the authors wanted to look at whether children (4-11 yrs old) living in an inner-city black community in Houston, Texas viewed their natural environment in a homocentric or biocentric way. They chose to study this group for two reasons. First of all, Houston is one of the most polluted cities in the United States and they wanted to explore their experiences under those living conditions. Secondly, there is very little research on black children's connectedness with nature. They used a hypothetical scenario involving the pollution of a local waterway. A bayou runs approximately one mile from the school attended by the children in the study and the researchers wanted to know how the children would react to different scenarios involving pollution in the bayou. Pictures of the scenarios were shown to the participating children and they were asked several questions regarding the morality of what the person in the picture was doing, their feelings about the pictures, and whether they felt it is right to pollute the bayou.

The results of this study found that the children showed an overall sensitivity to nature, awareness of the environmental degradation of their community, as well as an understanding of the importance of protecting it. The majority of the children applied 
homocentric thought in their description of why it would be bad to pollute the waterway. These findings imply that most of the children in this study perceive environmentally responsible behaviour as a means of self-preservation. They felt that keeping their environment free of pollution was in their best interest due to the health effects it would have on the population. Similar results were demonstrated in two other studies conducted by the authors (Howe, Kahn Jr., \& Friedman, 1996; Kahn Jr.and Lourenço, 2002).

Developmental trends were also found among these children. As participants increased in age, they displayed higher levels of environmental awareness (Kahn \& Friedman, 1995). These further studies served to strengthen Kahn Jr.'s findings that urban children have strong feelings about the protection of their environment. 


\section{Barriers to Environmentally Responsible Behaviour}

There are many possible reasons why an individual would not be inclined towards pro-environmental behaviour, but I will only be concentrating on three: Lack of environmental knowledge and awareness, lack of self-awareness, and ambivalence towards environmentally responsible behaviour. Environmental knowledge strongly influences the interpretation of a threat to the state of the environment. Rogan, O'Connor and Horwitz (2005) found that when participants had a strong understanding of their environmental situations, they had a stronger sense of place attachment. This higher connectedness with their surroundings was also found to encourage the decision to act in more environmentally responsible ways. Family and community members play fundamental roles in the development of environmental knowledge and awareness (Cohen, 1994; Rogan, O’Connor \& Horwitz, 2005). Knowledge and awareness of the different ways of caring for and protecting the environment can be fostered by family members and community organizations through story telling, nature walks, conservation efforts, etc.

The Rogan et al. (2005) article has brought to light many interesting details about the development of environmental knowledge. Although they contribute greatly to the field of environmental psychology through this research, the researchers fail to provide an explanation of what they considered to be knowledge. What constitutes environmental knowledge? Would it be measured by the amount of books one has read on the topic or by the amount of animal species that a person can identify? There are many ways that environmental knowledge can be measured and this information was not included in the methodology section of this study. It is fundamental for the proper understanding of their 
findings, that Rogan et al. provide a definition of what they consider to be environmental knowledge.

Being conscious of the future environmental consequences of our actions is another form of environmental awareness. Environmental problems are perceived as social dilemmas because they present a threat to the collective interest of the group and can lead to temporal conflicts (Milfont \& Gouveia, 2006). Temporal conflicts refer to the short versus long-term interests in preserving the natural environment. These stem from the realization that our past and current environmental actions have an impact on the future state of our environment. "Awareness of environmental problems and understanding the causes and consequences of environmental degradation, whether obtained from school or elsewhere, increases children's sense of achievement and responsibility" (Korhonen \& Lappalainen, 2004, p. 214).

Lack of self awareness is another element that can be detrimental to environmentally responsible behaviour. Frantz, Mayer, Norton, and Rock (2005) studied the effects of objective self-awareness on connectedness to nature among undergraduate students. Objective self-awareness is defined as the phenomenon of when the self becomes the figure of its own attention and detaches itself from its surroundings. According to Frantz et. al., when individuals see themselves as separate entities from the natural environment, they are expected to be less connected to nature and therefore less inclined to participate in conservation efforts. Connectedness to nature and environmental attitudes were measured by the Connectedness to Nature Scale (CNS) and the Objective Self-awareness Scale (OSAS). Frantz et. al. predicted that when students had high levels of objective self-awareness they would display a lower score on the CNS. Their findings 
support their hypothesis that a high level of objective self awareness was negatively correlated with connectedness to nature on their CNS scale. This correlation comes into question, however, because all those included as having high objective self awareness had previously expressed anti-environmental attitudes.

Positive environmental attitudes have recently been escalating (Costarelli \& Colloca 2004); however, an increase in environmentally responsible behaviour has not been established. Costarelli and Colloca (2004) reasoned that the explanation for why positive environmental attitudes did not lead to environmentally responsible behaviour was due to the phenomenon of environmental ambivalence. Environmental ambivalence is described as the simultaneous presence of both positive and negative attitudes about the natural environment. The authors state that these feelings of ambivalence are negatively correlated with the intention to behave responsible towards the environment. If an individual feels a high amount of ambivalence towards environmentally responsible behaviour, they will be less likely to behave responsibly towards the environment. Ambivalence comes from feelings of uncertainty with regard to the necessity of protecting the environment and these doubts are often fuelled by anti-environmental attitudes (Costarelli \& Colloca 2004). 
- 


\section{Urban VS Rural Environments}

There has been an ongoing debate with regard to the importance of children being exposed to the natural environment for their healthy development and the occurrence of differences between rural and urban children's experience of the natural environment. Exposure to the natural environment is often mentioned as a key factor in the comparison between urban and rural environments. In rural areas, children have more opportunity to participate in physical and social activities independently, which in turn helps promote healthier development (Evans, 2006). Evans goes on to say that the longer children spend in outdoor activities, the stronger the benefits. In a study conducted among Swiss children, it was found that increased exposure to local organisms (i.e., animals and plant life) was positively correlated with an increase in appreciation for their environment (Lindemann-Matthies, 2005). The study encouraged children aged 8 to 16 to pay closer attention to the animals and plants they saw on their way to school. It was found that the number of species identified was positively related to the level of compassion for them. Following this study, the children were more knowledgeable about their surroundings and displayed higher levels of appreciation and concern for the newly discovered species. Children who have a higher exposure to the natural environment have shown increased involvement in environmentally responsible behaviour, conservation knowledge, environmental attitudes, and animal husbandry (Cohen, 1994; Kruse \& Card, 2004; Pringle, Hakverdi, Cronin-Jones, \& Johnson, 2003).

Bixler, Floyd, and Hammitt (2002) studied the occurrence of childhood play experiences among adolescent youth. They predicted that participants who have had the opportunity to play in natural environments while they were children would express a 
stronger interest in environmental issues and be more environmentally responsible. Two studies were conducted with public high school students in the southern United States. Their findings suggest that childhood play in natural environments encouraged the development of environmental competencies. Environmental competencies are ways in which children can participate in environmentally responsible behaviour. More so, these competencies are determined by the abilities that the children feel they possess when it comes to preserving the natural environment (Bixler, Floyd, \& Hammitt, 2002). Although participants showed a preference for these types of environments, there was not a direct relationship between their play experiences in the natural environment and future interest in environmentalism. Frequent contact with nature was found to decrease the perceived complexities and uncertainties brought on by the state of the environment experienced by the participant. This contact was found to increase their preference for such locations. The authors conclude by suggesting that if children are to develop an interest in environmental issues, early play experiences in these environments could be beneficial. If children are given the opportunity to play in natural settings early in life, they may develop stronger feelings towards the natural environment and feel more competent in their conservations efforts (Bixler, Floyd, \& Hammitt, 2002).

A similar study was conducted by Palmer, Suggate, Robottom, and Hart (1999). They wanted to see what significant life experiences lead to the development of environmental concern among Australian, British and Canadian environmental educators. Among all three sample groups, early childhood experience in nature was recognized as the most influential factor in developing responsible attitudes towards the environment (Palmer et. al., 1999) 
Subsequent studies of adolescent experiences in both rural and urban environments, found that there were no significant differences in the preference for natural settings between an urban and a rural upbringing. This evidence suggests that there isn't a unitary childhood experience of nature and that urban and rural children may share similar preferences for natural environments (Cohen, Horm-Wingerd, 1994; Nairn, Panelli, \& McCormack, 2003). This is described as the 'myth of rural childhood' where Nairn et. al. discuss the problems involved when we see childhood in such a generalized way. When we generalize childhood experiences, we neglect to consider individual differences in how children view the environment. It is important, for this field of research, that we look at how each individual experiences their natural environment in order to properly understand the different ways in which people internalize their surroundings.

Although there is strong literary support for the exposure to natural environments in the development of childhood environmental advocacy, Eagles and Demare (1999) have ascertained that this type of exposure does not always result in pro-environmental attitudes. They studied the occurrence of ecologistic or moralistic attitudes among sixth grade students after attending a week-long residential camp program. The children were found to have entered the program with their own prior knowledge about the environment and did not benefit from the exposure to new animals and plant species.

A critique of Bixler, Floyd, and Hammitt (2002) and Nairn, Panelli, and McCormack (2003) is that they should specify the differences between nature and the natural environment. Both studies use these terms interchangeably without a distinction of their differences in definitions. Nature, in my opinion, refers to the ecological aspects 
of our environment. I believe that these authors are referring to the natural environment, which would be defined as the natural aspects of the environment in which we live. Nature can be seen as completely different from the natural environment. To a child living in the city, the natural environment is the community park or nearby green belt, but to a child living in the country, the definition of this environment may be very different.

Cohen and Horm-Wingerd (1993) also found that there was little difference between how children view the environment based on their locations. They collected data from 88 preschool children aged from 3 to 5 years. The children attended either an urban Jewish community childcare centre or a rural Rhode Island childcare centre. The authors used artistically rendered drawings of ecologically destructive scenarios to assist the children in visualizing the events beings measured. They asked the children to compare drawings such as two identical natural scenes, with one containing evidence of pollution. They were also asked to respond to researcher questions concerning the scenes illustrated in the drawings. Cohen and Horm-Wingerd accounted for the validity of their data by ensuring that the scenarios selected for the exercise depicted an array of common ecological problems that would be known to the participants. It was found that both urban and rural children were able to respond to ecologically formulated dilemmas and could display an understanding of the effects of pollution on the natural environment.

Additional support for urban environments is provided by Kearny (2006). She established that although urban areas do not include many natural environments, the presence of shared green spaces can help to rectify some of the negative effects brought on by residential density and overcrowding. Physical proximity to natural spaces within the city of Seattle, Washington, USA, was also found to increase feelings of 
neighbourhood satisfaction or place attachment (Kearny, 2006), and as mentioned previously, this attachment is said to increase environmentally responsible behaviour. Van Velsor and Nilon (2006) offer some insight into the development of appreciation for wildlife among urban adolescent youth. Although the participants in their study demonstrated varied levels of interest and appreciation for wildlife, ranging from active interest and engagement to complete disinterest, the authors suggest that this does not have to be the case if certain elements are in place. If urban children are given access to natural environments, receive supportive wildlife mentoring from adults and have positive encounters with a variety of wildlife, they will be just as appreciative of the natural environment and wildlife as their rural counterparts (van Velsor \& Nilon, 2006). 


$$
\text { . }
$$




\section{Environmental Education}

A lack of education is one of the largest obstacles to pro-environmental behaviour. If we are not able to recognize what things are harmful to the environment, how can we begin to preserve it? Access to this information is not enough to ensure that positive environmental attitudes are instilled. Young children must be given the opportunity to comprehend and identify with the information so that they can absorb it (Barraza \& Walford, 2002). In the field of environmental education, there are two distinct streams. The first concentrates on scientific knowledge and offers technical solutions to environmental problems. The second centers more on the compassion aspect of environmental protection and seeks to inspire a sense of responsibility (Chawla, 2006).

The primary goal of environmental and wildlife education is to build a populace that is knowledgeable about the environment and aware of the problems involved (Adelman, Falk, \& James, 2000; Ballantyne, \& Bain, 1995; Folsom, Hunt, Cavicchio,

Schoenemann, \& D’Amato, 2007; Lindemann-Matthies, 2002; Vaughan, Gack, Solorazano, \& Ray, 2003). Children should be taught about the environment through examples taken from their own natural environment instead of remote locations that they may never have the chance to see (Korhonen \& Lappalainen, 2004). Fisman (2005) measured the effects of an urban environmental education program on participants' awareness of their local environment. More specifically, she looked at how children in grades 3 and 5 responded to the "Open spaces as Learning Places" program, which was administered throughout several schools in the state of New York, USA. Following the administration of the "Open spaces as Learning Places" program, the children 
demonstrated a higher understanding and awareness of local environmental spaces and concepts.

As part of the program, the children were asked to draw a map of their neighbourhood at the beginning and once again upon completion of the program. During the program, the students were also asked to identify a "special tree" near their home. This activity was found to strongly influence the post-program drawings. The children's images, provided in the article, were drastically different after they had completed the program. The "special trees," which had not been included in their original maps, had become the centre of attention in the post-program maps. 


\section{Implications of the Literature for this Study}

The literature discussed in this review has served to help me better understand what has been studied in this field, and also to see where there may be some gaps. In order to attempt to fill these gaps, I will be using the information from these previous studies to assist in the development of my own hypotheses. Current studies on childhood experiences of the natural environment have shown that there are many factors that can influence the occurrence of environmentally responsible behaviour (i.e., increased ambivalence, lack of self awareness, lack of environmental knowledge). Although these issues are all interesting and worthy of study, I will be concentrating on how children in Toronto and Georgetown, Ontario view their natural environment and perceive their ability to make a difference through environmental advocacy. Lack of environmental knowledge and accessibility to green spaces are the particular factors that I will be focusing on in this study.

Through this research project, I hope to contribute to the body of knowledge on urban and rural environments and how these can be used to promote pro-environmental behaviour among residents of larger cities where there is a need for "greenness." The lack of natural stimulation and exposure in early childhood has been the subject of debate in the field of environmental psychology, and my aim for this study is to identify whether "location specific" methods to help all children better understand and appreciate their natural environments are necessary. When children grasp the importance of preserving the natural environment and understand the severity of the problems caused by environmental degradation, they will grow up with higher levels of awareness of the 
consequences of human actions and are more likely to act in environmentally responsible ways (Korhonen \& Lappalainen, 2004). 


\section{$\underline{\text { Researcher Self-Disclosure }}$}

As a researcher, I have selected to pursue a social-constructivist role. This research paradigm does not assume that there is one, absolute reality that is worthy of study. Social-constructivist researchers are more concerned about how individuals, children in this case, construct their own realities. Social-constructivists believe that children make sense of their experiences through these constructed realities (BarclayMcLaughlin, \& Hatch, 2005). Social-constructivist scholars question the idea of objective facts. The role of language in the perspective of social-constructivism is not to work as a picture or a map of what had happened. Social-constructivist does not question the existence of a reality 'out there', but emphasizes people's relation to it. What it means to people (Falkheimer \& Heide, 2006). I feel that in order to understand children and their experiences, we must look at the individual child's constructed world.

This research study will be done in a qualitative fashion. Qualitative research implies an emphasis on qualities that are not examined experimentally or measured numerically. Qualitative study considers knowledge and experience to be context-specific where the individual constructs their own reality (Hillcoat, Forge, Fien, \& Baker, 1995). In my opinion, children form their own unique ideas of nature and the ways of preserving it, and I wish to capture this in my research. I chose to use a qualitative approach because I expect that this type of research cannot be effectively conducted through quantitative inquiry alone. Children's experiences of the natural environment are not necessarily best quantifiable into proportions and frequencies and I feel that previous research in this field has neglected to explore this method of study. Much of the research done in this area has relied on quantitative methods and has focused on the assessment of perceived 
environmental quality by using mathematical methods based on classical psychophysics (Daniel, 1990).

The strategy used to help answer my research questions is grounded theory. This theory is a qualitative design in which the researcher finds a general explanation or theory of a process or interaction from the views of a large number of participants (Creswell, Hanson, Clark-Plano, \& Morales, 2007). This method emphasises the views and experiences of participants and produces a strong body of data by exploring several methods of collecting it. Overarching themes are drawn from the data in order to formulate theories in regards to the phenomenon in question. I believed that this strategy would best serve to help develop my theories as to whether urban and rural children differ in their views of the natural environment, and this is why I have not chosen a position in this matter as of yet. The literature is inconclusive and I aspired to explore further the questions of whether the children in my samples saw the environment and its protection in a different way. My aim was to have the data "speak to me". What I mean by this is that I will find general themes within the data from the children's explanations, in order to help investigate the themes in question. I will not infer on what the children are saying, instead, I will ask them exactly what they intended to convey in their drawings and statements.

My personal experiences and views have had a strong influence in the selection of this research topic. I feel very strongly that the natural environment is in danger of destruction and believe that something must be done to help preserve it. My environmental views have lead to an interest in children's views of the environment. I feel that by teaching children basic environmentally responsible behaviours, we can aid 
them in their struggle to have a clean world to grow up in. Children are the "keys to the future of the planet" and they must be taught appropriate conservation methods in order to complete this duty. By appropriate methods, I mean that not all children experience the environment in the same way and the environmentally responsible behaviours that are available to some children may not be available to others. My own childhood was predominantly spent in rural areas and I have learned to respect nature through this repeated contact. I have had many opportunities to experience nature and I feel that this has led me to have positive views of the environment. 



\section{Scope and Focus}

This study was conducted over three months, between May and August 2007. Data collection began as soon as the Ryerson Research Ethics Board granted my request for approval. The duration of this study was limited to three months due to the requirement to complete this research paper by the end of the summer of 2007. These time restrictions meant that I was not able to focus on all of the topics that I initially intended to include. The two factors that I observed among both groups of children were their views of the natural environment and their knowledge about environmentally responsible behaviours. Specifically, I wanted to look at what children know about nature and how they feel about it. I also wanted to observe whether they were aware of ways that they can preserve the natural environment and if they displayed confidence in their abilities to do so. Environmental knowledge is considered in this study to be all the elements that they mention as being part of the environment. A compilation of the items mentioned by each participant served as a basis for their knowledge of nature. In order to examine these factors, I utilized a triangulation method. This method was intended to capture multiple perspectives though the use of different data collection tools (Morrow, 2005). The data collection tools that I employed were drawing analysis and semistructured interviews. I asked the children to draw a picture of their natural environment. Probing questions like "How do you see the natural environment?" and "What does the environment mean to you?" were used to help the participants understand what it was that I was asking them to draw. I believe that this was an effective method of having the children share their views of the natural environment with me. Drawings gave them the opportunity to visually explore what the environment meant to them and also provided 
tangible data for my further analysis. The semi-structured interviews consisted of a list of guiding questions that I asked the children as we proceed with the interview. Questions asked the children to express their feelings about the environment and what they think they can do to help protect it. This type of interview was used to explore the child's knowledge about their natural environment and I feel that it was a valuable way to answer my second research question. I did not feel that it would be very effective to observe knowledge of environmentally responsible behaviour among the children by analysing their drawings alone. A more in depth portrayal of the child's knowledge was needed so as to ensure that the data collected was trustworthy. 


\section{Setting and Sample}

This study was conducted within the Greater Toronto Area. Two elementary schools were initially selected as the sample for this study, one in Georgetown, Ontario, Canada and the other in Toronto, Ontario, Canada. One school was chosen due to its rural location and the other because it is located in an urban area. Both schools belong to a French school board where most of the teaching and communication is done in French. Personal contacts at both schools assisted in helping me obtain permission to recruit students from these schools.

My choice of schools reflected my desire to study the phenomenon of difference between rural and urban children. They are located in areas that represent the ecological landscape required to compare these groups based on location. The rural school is located in the Toronto down town core, and the rural school is located in the town of Georgetown. I was interested in observing the occurrence of a difference in environmental views and knowledge between rural and urban children aged 6-8 years. This age group was chosen because I felt that they would already have the necessary knowledge to answer the questions required of their participation.

Letters were sent home with the children aged between 6-8 years in grades 1 though 3. I also visited the school to introduce myself to the parents who wished to ask questions. Parents were given the choice of location for the study. The interviews and drawing activities were conducted either in the child's home, or in some instances for the rural sample, were conducted in the school at the parent's discretion. The first five parents in the rural setting to express an interest in having their children participate in the study were selected as the rural sample. Five participants ( 4 girls, 1 boy) were recruited 
from the school community in Georgetown. Unfortunately, due to a lack of response from the parents in the Toronto sample, a new method was applied to recruit children for the urban portion of the study. For the urban sample, personal contacts in Toronto were asked to help with the recruitment process. Letters were sent home with these contacts and were then distributed among their community. To ascertain the ethical consideration of the participants and their parents, I requested that they contact me should they and their child wish to participate. This was done to ensure that the parents did not feel coerced into participating in the study. Parents in both sample groups, who were interested in participating, were given consent forms to sign on the day of the study (see appendix A).

With this added recruitment method, I was able to find four children to complete my urban group ( 2 girls, 2 boys). Only four parents responded to my request in time to be included in this study. I feel that I have collected enough data from both sample groups to confidently generate ideas about what these children know about the environment. I am a student researcher and consequently this study is subjected to temporal limitations. This is why only a total sample of 9 participants was recruited for this study. Although this is a small group of participants, it is considered to be a significant sample within qualitative research.

"Numbers have little to do with the quality or adequacy of qualitative data" (Morrow, 2005, p. 255). This stratified purposive sample is designed to exhibit a variation on a particular phenomenon while still remaining rather homogeneous so that the subgroups can be compared. The subgroups in this study are represented by the different locations selected for the sample. This factor has been isolated to effectively examine the difference between the children in both groups. 


\section{Table 1}

\section{$\underline{\text { Age and Gender for Both Samples }}$}

\section{Rural Sample}

R1: 6yrs / Female

R2: 8yrs / Female

R3: 8yrs / Male

R4: 7yrs / Female

R5: 6 yrs / Female
Urban Sample

U1: 8yrs / Female

U2: 8yrs / Female

U3: 6yrs / Male

U4: 6yrs / Male

In order to comply with the ethical considerations of the chosen settings and the sample, I first followed the ethical guidelines of the school board involved in both sample groups. I believe that the research sites were respected and honoured to the best of my abilities. Confidentiality was kept throughout the study with the use of coding to identify the different participants. The urban children were labelled U1-U4, and the rural children were labelled R1-R5 for the purposes of my own organization. All children and their parents were given the opportunity to refuse their participation at any time, and were offered the chance to change or withdraw any aspect of their data, up until the submission of my research paper (Creswell, 2005). 



\section{$\underline{\text { Data Collection Procedures }}$}

The drawing exercises and interviews were conducted on a one-on-one basis with the children. Parents were invited to attend if they chose or if their child requested their presence. For the drawing exercise, participants were seated at a table and were asked to draw a picture of the environment. They were provided with a wide array of colouring materials and paper. I asked them to show me what the environment is to them. I sat next to them while they drew in order to observe. Once they had completed their drawings, I asked the children to describe and explain to me the meaning behind their pictures. This was done to ensure that I had properly interpreted this portion of their data. Probing questions such as, "What is that?" and "What is happening in this picture?" were used to help the children further describe them. The interviews were also conducted as the children sat at a table with me. The audio recording device was placed on the table surface, near the child, so as to best record their responses. This was a semi-structured interview process and guiding questions were used to explore the children's knowledge of the environment (i.e., "Can you tell me about the environment?", "How do you feel about nature?" and "What sorts of things can we do to help the environment?"). The interviews and drawings lasted between 30 minutes to an hour each. The duration depended on the amount of information the child wished to share with me, and the length of time they took to complete their drawings. 


\section{Data Recording and Organization}

Data collected from the drawing activity was manually recorded through researcher note taking. I observed the children as they drew the pictures and took field notes of the explanations and narratives they provided. The interview data was audio recorded and transcribed into a written document for the researcher's usage in the analysis process. Due to the language requirements of the rural school, all letters, consent forms, drawing exercises and interviews were initially presented in French. These interviews were then translated and transcribed in English to the best of my abilities. All field notes, drawings, and interview transcripts were kept together in separate folders for each child. These folders ensured that the data from each child was kept separate from each other. During the study as well as for a full year after completion, I will be storing the complete data sets (child folders) in a locked cabinet in my home. My supervisor and I will be the only individuals who will have access to the names of the participants in relation to their data. This will further guarantee ethical consideration regarding participant confidentiality. 


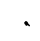




\section{Data Analysis and Interpretation}

The initial analysis was first done by immersing myself in the data. This was done through repeated reading and viewing of the drawings and transcripts (see appendix B, C, $\mathrm{D}$ and $\mathrm{E})$. "These repeated forays into the data ultimately lead the investigator to a deep understanding of all that comprises the data corpus and how its parts interrelate" (Morrow, 2005, p. 256). According to grounded theory, the researcher allows the themes and theories to develop from the data. The researcher embarks on a study with a basic understanding of the phenomenon, but does not necessarily occupy themselves with finding similar themes. The underlying ideas are brought out and themes are then formulated to assess a fit within the literature.

Codes were then assigned to each theme I uncovered and were used to categorize the data into these groups. Coloured highlighters and adhesive notes served to help keep the coding process organised and comprehensive for myself and my supervisor's convenience. Once the codes were assigned, I began grouping the items from each theme together to investigate the phenomenon and to attempt to answer my research questions. I then was able to make some conclusions about whether children from rural and urban settings differed in their views of the natural environment based on what I had observed.

My interpretation was carried out in a way that ensured the best possible trustworthiness of my findings. My personal feelings in regards to environmental issues may influence the way in which I see the different themes uncovered in the data. Through researcher reflexivity, I feel that I will be able to distance myself from my own biases to see the opinions of the children come through on their own. My MRP supervisor was asked to serve as an external auditor to review the data and coding system. This was done 
to confirm that the interpretation was not been skewed to fit my own research objectives. Throughout the course of data collection and analysis, I kept reflective notes of my opinions about what I saw unfolding in the data, and any other items that came up that needed further exploration. This method of memoing is described by Creswell (2005) as a means of accounting for researcher biases and of encouraging researcher reflexivity.

As a student, I am continuously learning new ways of studying children. In a course on social research with children, I have learned that research conducted with children as opposed to on children (emphasis is mine) is a much more ethical way of studying their experiences. This class has allowed me to appreciate that children should be considered as active participants in the research process. In order to ensure that their responses were not skewed or distorted by my interpretations, I made an effort to confirm and re-confirm the meaning of the data with the children during the collection process. This method has helped in assuring the accuracy of my understanding of what the children are saying and also serves to promote the trustworthiness of my findings. 


\section{Dissemination of Findings}

Prior to disseminating my findings, I will be assessing my efforts at accurately sharing the children's views with others in a similar way to that which they have shared it with me. Dissemination must be free of modified or altered data and this assessment process will allow me to evaluate whether I have respected the children's rights as participants. It is my intention to attempt to have this research published and I will work towards preparing a document that is worthy of this honour. The purpose of sharing this information with other academics will be to further the collective body of knowledge about rural and urban children's views of the environment, and to hopefully encourage additional research in this area. As mentioned in the literature review portion of this study, there have not been many studies done in this specific area and it would be a benefit to the field of environmental psychology if research was done to refine our knowledge of this phenomenon. The second target audience for the dissemination of this research study is School Boards and the Ministry of Education. If my findings show that urban and rural children experience the environment in different ways, the environmental curriculum offered in both these types of school could benefit from this knowledge. Location specific methods of teaching about environmental preservation can be useful in encouraging the development of environmentally responsible behaviours among all children, no matter where they live. 



\section{$\underline{\text { Results }}$}

The amount of material collected throughout this research study was plentiful, as well as having both diverse and similar qualities. In order to present the results in a comprehensible manner, I have divided the data into two sections, one for each location. The themes that arose from the data analysis were then used as groups in each section. The major themes identified were: animals, natural elements, man made structures, and environmentally responsible behaviour. The first theme, animals, consisted of all mentions of animals within the data. The second theme, natural elements, consisted of everything that was drawn or mentioned that was part of the natural environment, excluding animals. The third theme, man made structures, consisted of all the structures or buildings that were depicted by the children. Finally, the fourth theme, environmentally responsible behaviour, consisted of three elements: awareness of environmental problems, knowledge of conservation methods, and feelings of selfefficacy in behaving responsibly towards the natural environment.

\section{$\underline{\text { Urban Sample }}$}

$\underline{\text { Animals }}$

Drawings: Animals were depicted by the children in the urban sample in two pictures. The first drawing shows the destructive effects of pollution on a deer. In the drawing, the deer goes through four steps. First the deer is alive, secondly it smells pollution in the air, thirdly it chokes on the pollution, and finally the deer dies. The second drawing that involved animals in this sample portrays a scene where an eagle, a fox, a donkey and an alligator are getting along. After further explanation, it was revealed 
that these animals were having a meeting to discuss the problem of animals keeping to their own kind. This child titled the drawing "The invierment (sic) to me is animals."

Interviews: Animals were mentioned by all four children in the urban sample as being a rather important part of the environment. The children were aware of many different species of animals and seemed to harbour strong feelings towards their protection and welfare. The children also mentioned the treatment of animals in zoos, and the effects of hunting and pollution in regards to wildlife in general.

\section{Natural Elements}

Drawings: Natural elements were seen in three of the four drawings, with one of particular interest. In the same drawing as was described above, along with the deer, a flower goes through similar steps from healthy to death as a result of exposure to airborne pollution. In the other two drawings, the children presented what I would call "everyday natural elements." These are items, concepts or scenes of which, in my opinion, are most commonly seen as natural elements, (i.e.: trees, the sun, clouds, grass, etc...). In these scenes, the elements all fit into the traditional 'mould' that is usually identified with natural settings (i.e.: sun in the sky, grass on the ground, trees growing upwards etc...).

Interviews: 'Everyday natural elements' were mentioned by all four urban children over the course of the interviews. Trees, plants, flowers, the solar system, apples, and leaves are examples of the elements of the natural environment discussed.

\section{Man Made Structures}

Drawings: In the aforementioned drawing consisting of the death of a deer and flower due to pollution, two cars are drawn with exhaust pumping out of the tailpipe. When asked what these cars represented, the child indicated the canoe on the roof of the 
first car and said "They are going on vacation to Florida." The second drawing that included a man made structure was a drawing of the child's school. He made a point of drawing a horizontal line through the centre of the school to indicate that there were two floors and that his classroom was on the second floor.

Interviews: Man made structures were mentioned in three of the four interviews. Cars, taxis, highways, houses, fences, brick walls, the subway and Toronto Transit Commission, The Beer Store, The Toronto Metro Zoo, The Ontario Science Centre and city parks are examples of man made structures mentioned by the urban children. Environmentally Responsible Behaviour

Drawings: There were two elements that were considered to be environmentally responsible behaviours within the drawings for this sample. These elements were found in two of the four urban drawings (U1 and $\mathrm{U} 2$ ). The various effects of airborne pollution on the environment illustrated by the deaths of the deer and flower and the awareness of a problem with animals not getting along within their natural settings were both considered to be depictions of environmentally responsible behaviour according to description of this theme.

Interviews: Due to the variety of mentioned environmentally responsible behaviours within all four interviews, I will be sharing each child's understanding and conception of this theme separately. U1 discussed environmental problems such as the hunting and poaching of rare animals, littering, pollution, and car exhaust as a pollutant. This child expressed that they could help the environment by stopping poachers, advising others to not litter, and to encourage the use of cars that do not produce exhaust. U2 also stated problems with hunting for sport, the mistreatment of animals in foreign smaller 
zoos, the use of plants to make harmful substances like illicit drugs, littering, and the desecration of property caused by graffiti. $\mathrm{U} 2$ feels that she can help the environment by donating money to charities that advertise on television about the protection of animals, encouraging others to not only clean up on one day of the year, but to do this everyday, and to gather a group of individuals together to demonstrate their frustration about the amount of littering that is happening. U3 was aware of environmental problems such as littering and its effect on bugs and other wildlife "(in regards to litter on the ground)...when ants chew it up, it makes then a little bit sick, but they're not allowed to eat plastic and all that stuff...". To help the environment, this child felt that he wanted to go on a television program called City TV and express himself in regards to his frustration with the amount of littering in the city of Toronto. He also expressed the desire to make it a law that travel on highways is not permitted to drivers who throw trash out the windows of their cars. U4 shared similar frustration with litter on the ground and also felt that legal action should be taken to prevent this from happening. He stated that litter is pollution and that pollution makes the environment die because we will no longer have any oxygen to breath. His methods of environmentally responsible behaviours included speaking out about littering and pollution, putting things in recycling bins, and helping trees and plants to survive by caring for them. All the urban children in this study demonstrated, in my opinion, strong feelings of self-efficacy with regard to their abilities to behave responsibly towards the environment. They spoke with confidence about the many ways that they and the general population can help keep the environment clean. 


\section{Rural Sample}

$\underline{\text { Animals }}$

Drawings: Animals were illustrated by the rural children in what would seem to me as natural settings. This depiction of wildlife is different from the urban children's drawings in that the urban children showed more abstract conditions. Five out of six of the rural drawings illustrated animals in their natural settings (R1, R3, R4, R5a and b). A horse grazing in an open field, a rabbit with a carrot, a butterfly flying around next to a frog sitting in a pond, and a woman walking a dog are examples of how animals were represented in the rural children's drawings.

Interviews: The mention of animals by the rural children was very limited. They included certain species of animals as being part of the environment, but did not go into great detail about them. One child stated that what she did not like about the environment were snakes and spiders, but that she was very fond of frogs.

\section{$\underline{\text { Natural Elements }}$}

Drawings: The 'everyday natural elements' identified earlier were present among all the rural drawings. The sky, clouds, the sun, the grass, and trees were all prominent aspects of each drawing.

Interviews: The same 'everyday natural elements' were represented in the interviews with the rural children. They expressed that these elements are part of the natural environment and some shared pleasurable experiences or feelings that arose from these. For example, a child mentioned that he visits the forest with his grandfather on a regular basis and enjoys these times, and another child expressed that she liked nature 
when it is all clean and free of litter. One particular child expressed a distaste for clouds “...because it can rain."

\section{$\underline{\text { Man Made Structures }}$}

Drawings: Man made structures were only depicted by one child in the rural sample. This particular child chose to draw two scenarios. The first drawing is of a school with a path running behind it. The second scene is of a farm belonging to this particular child with a road in the background.

Interviews: The man made structures identified by the rural children as being part of the natural environment were also not plentiful. One child included asphalt and houses as part of the environment, while another spoke of schools, sidewalks, stores, cars, hotels, toys and countries.

\section{Environmentally Responsible Behaviour}

Drawings: Among the drawings, only one child contributed to this theme. The child in question drew herself picking up trash and putting it in a large recycling bin. The environmentally responsible act of picking up trash and recycling it is evident within this picture.

Interviews: The child who provided the drawing mentioned above spoke passionately of recycling being a major problem and that if there is too much trash, the earth's climate will change. "It (recycling) helps the earth, so there is not so much trash because if so, it will be very hot in the future..." Three of the other rural children mentioned similar ways of helping the environment (i.e., watering plants, planting more trees and plants, feeding animals, and one of these three children talked about picking up trash). 


\section{$\underline{\text { Discussion }}$}

To best examine the data accumulated during this research study, I will once again break down my findings by theme. The children's knowledge and experiences of animals, natural elements, and man made structures will be discussed individually so as to evaluate the similarities and differences within the data from both the urban and rural samples. Thereafter, the various aspects of environmentally responsible behaviour expressed by the children will be examined in three sections; knowledge of environmental problems, environmentally responsible behaviour, and their perceived capability of being environmental advocates.

\section{Animals:}

The urban children's knowledge of animal species and welfare seemed to me very detailed. Between the drawings and the interview material, one can infer that the urban children in this sample are very passionate about wildlife. They recognize that animals are part of the natural environment and acknowledge that humans must care for them if they are to survive. Numerous different species of animals were mentioned by the urban children, demonstrating their heightened knowledge in this area. Their image of nature involves animals who are obviously not part of their personal environment. This discrepancy between views of wildlife in nature can be attributed to the fact that children who live in rural settings are exposed to a wider variety of indigenous animal species and can visualise them in the natural environment in a more concrete fashion. The urban children in this study have displayed an abstract concept of wildlife. This concept may have been developed through the need to create tangible scenarios for them to better 
understand the role that animals play in the environment. The zoo was mentioned by two of the urban children in regards to animals and the equity of their treatment. "Like every time you go to the zoo, you figure out something new" (response by U2 with regard to what she liked about the environment). The inclusion of a place, within their environment, where they can see and interact with exotic animals in an urban setting, says to me that they understand that animals are part of their natural environment, but they may not fully conceptualise the presence of animals native to the Toronto area.

One of the major differences that I have found between the animal knowledge presented by both groups was the incredible amount of passion the urban children harboured for wildlife and their protection. The rural sample shared methods of keeping the animals happy as a way of helping the environment, whereas the urban sample identified problems that the animals were facing, and offered some solutions to help alleviate these dilemmas. Both groups shared interest in feeding and caring for animals, but only in the urban sample can we really identify elements of devotion to their cause. Myers, Saunders, and Garrett (2004) described the child with this level of devotion as the "animal aficionado." The "animal aficionado" or animal enthusiast dedicates themselves to the understanding and caring for animals species of all kinds. In their study, Myers et. al. found that these "aficionados" were attracted to lesser-known animal species like bats or koalas. These findings are similar to my urban sample in that the children listed mostly rare or foreign creatures as opposed to common local species as did the rural group. According to Meyers et. al., this fascination with the exotic demonstrates “...a developmentally-favoured route to the ultimate destination of an ecological ethic" (p.559). What they are saying is that these children are on the road to higher 
understanding of what it means to be environmentally responsible. The rural children seem to have more realistic images of animals in nature and from their drawings I can infer that they perceive them as having a role within nature, but that this role is idealistic in that it is harmonious and free of danger. All the animals mentioned by the rural sample are well known species in the area and the image they set for them is one of general harmony and contentment in their environment.

The urban sample on the other hand spoke of poachers and hunters killing animals for sport and expressed concern for their wellbeing. "They're hunting animals and it's not nice, and they made it, I mean God made nature and they shouldn't be hunting them" (U2 commenting about why she does not like poachers). "It's the ...the environment is um...um...when you throw something out on the um...on the...on the street and and when ants chew it up its makes then a little bit sick, but they're not allowed to eat plastic and all that stuff. They're only allowed to eat apple scraps, banana peels, watermelon seeds if they're dark..." (U3 commenting on how insects are affected by the litter and plastic that people throw on the ground). It seems to me that these children, U3 in particular, are very aware of the consequences we can have on the health and welfare of animals. Rather than mentioning ways of helping the animals stay happy, the urban children offered real life solutions to the concerns they have about the welfare of local and exotic animals alike. Kahn and Friedman (1995) describe this thought pattern as having biocentric considerations for the environment. This mentality attributes values and rights to nature, animals in this case, and stems from the children's environmental moral reasoning. Evidence of biocentric thought is found throughout the urban interview data. 


\section{Natural Elements:}

The everyday natural elements frequently described by the children in both groups demonstrate that they have a general knowledge of the elements of nature. The constancy of their mention indicates that these elements make up the core of the children's view of nature. This is described by Hyun (2005) as the inherent aspects of nature that serve to help children develop their own environmental constructions. Their experience with nature contributes to their body of knowledge about the environment and acts as a kind of template for future reference (Hyun, 2005). It seems to me that both the rural and urban children possess very similar ecological templates and consider the same "everyday natural elements" as part of their environments.

One particular child in the rural group expressed a certain pride for the forest in which he and his grandfather visited. He said that he felt proud of the forest and of what his grandfather teaches him. Family members are often useful in fostering proenvironmental attitudes and behaviours among children (Ballantyne, Connell, \& Fien, 1998; Cohen, 1994; Eagles, \& Demare, 1999; Howe, Kahn, Jr., \& Friedman, 1996; Knussen, Yule, MacKenzie, \& Wells, 2004; Palmer, Suggate, Robottom, \& Hart, 1999; Vaughan, Back, Solorazano, \& Ray, 2003). Parents, especially, are extremely influential in their children's lives and environmental beliefs are no exception. The Canadian environmental education teachers from the Palmer, Suggate, Robottom, and Hart (1999) study mentioned that their family members were the second most influential factor in the formation of their environmental awareness and concerns. 


\section{Man Made Structures:}

Although man made structures have made appearances in both the rural and urban data, I feel that they were represented in very different ways. The rural children mentioned man made structures such as houses, schools, sidewalks, cars, farms, roads and asphalt. The urban children included similar structures such as cars, schools, and highways but also included structures within Toronto that they associated with the environment. The Metro Toronto Zoo and the Ontario Science Centre were mentioned as well as Go Transit Trains and The Toronto Transit Commission. Of particular interest, an urban child made reference to the 'Beer Store' to distinguish the location of a particular park in his neighbourhood. It appears to me that the urban children connected these man made structures with the natural environment because they were either present amongst the natural settings they experience in the city, or were places that they could visit to learn more about it. One urban participant said that "Sometimes animals are treated well, like in zoos like the Metro Toronto Zoo and some things are horribly treated like in little tiny zoos like in Romania or some place like that. And plants should definitely be treated better, cause I see a lot of people, like at the Metro Toronto Zoo there's this headquarters place where there's all kinds of animal furs that people are like taking and weird kinds of plants." This child has been exposed to this information through her visits to the Metro Toronto Zoo and these lessons have obviously left an impression on her. We could even say that her awareness of the natural environment has been influenced by this man made structure. This type of connection to the urban environment is what Smith and Bugni (2006) describe as symbolic interaction with architecture. This refers to the architectural aspects of the urban city environment and how residents develop a sense of attraction to 
them. They explain that, just like people in rural areas, the self identity of the urban dweller becomes intertwined with the physical environment (Smith \& Bugni, 2006). These relationships are considered to be equally influential in the development of environmental knowledge.

It is interesting to note that not only are there two drawings of schools within the data I have collected, but that they were drawn by one child in each location. The rural child's drawing included a school with a lady standing next to it. There was also a path with another lady walking a dog behind it. When asked what the structure was, the little girl replied that it was a school and that the lady was standing next to it. The urban child's drawing included a school with two floors with trees and grass. The child also wrote the name of the particular school on the front of the building. When asked what the drawing represented, he said that it was his school and that his class was on the second floor.

The difference in the concepts behind these two drawings is apparent from the children's explanations. The rural child sees the structure as a school, but not her school in particular (emphasis mine). The person standing next to the school is not meant to represent herself so I feel that she is in no way meaning to indicate that this is a place that is in her actual environment. The urban child on the other hand has made it evident that this is the school that he attends and that a second floor was necessary since he had to climb the stairs to find his classroom. This boy even described the trees in his drawing as being the specific trees that are growing in the school yard. If you look at the drawing (labelled U3), you will notice that the tree to the left of the school has fewer leaves on it. The child explained to me that this tree has fewer leaves because it lost them (see appendix B). 


\section{Environmentally Responsible Behaviour:}

The data collected that were associated with this theme were very diverse and I felt that further subgroups would best serve to organize the discussion of their properties. My findings were categorized in three subgroups: knowledge of environmental problems, knowledge of environmentally responsible behaviour, and children as environmental advocates.

Knowledge of environmental problems: There were children in both samples who spoke of environmental problems, but there was an imbalance of representation between both groups. The rural child, R2, who drew a picture of herself recycling, spoke fervently about the destructive effects of litter on the environment, the earth's climate and aesthetic properties but was unfortunately the only child to mention these problems among the five children who participated. She stated that “One thing that I really don't like is when there is trash on the ground because it makes me feel that the earth is going to be rotten and full of trash." Although the other rural children shared ways of helping the environment, they did not speak of the reasons they felt these measures were necessary.

The urban children collectively identified a large assortment of environmental problems. This discrepancy disputes what Cohen and Horm-Wingerd found in their 1993 study on ecological awareness. The rural and urban children in their study did not differ in their knowledge of ecological issues, whereas the children in my study have displayed major differences. A possible explanation for why the urban children have a stronger sense of the environmental problems we face could be that they are more exposed to these situations and relate more closely to them than do the children in the rural sample 
(van Liere, \& Dunlap, 1980). The more exposure to ecological dilemmas, the more appreciation the child will have for what natural resources we have left (LindemannMatthies, 2005; Pringle, Hakverdi, Cronin-Jones, \& Johnson, 2003). Furthermore, these increased feelings of empathy for wildlife and plant life will promote stronger environmental behaviours and attitudes (Berenguer, 2007). What is also noteworthy is the acknowledgment of the temporal consequences of our behaviour. In both data sets, we find that the children have made a connection between what we are doing now and the future environmental costs. When these temporal consequences are recognized, it is said to encourage environmentally responsible behaviour (Milfont, \& Gouveia, 2006).

Environmental education has utilized this way of understanding ecological problems so as to help enhance environmental conceptions. This is done by illuminating the future effects of environmental degradation in order to create a sort of cognitive conflict within the individual. This structured controversy approach has been successful in changing the way people perceive their future actions (Ballantyne, \& Bain, 1995).

Knowledge of environmentally responsible behaviour: The responses I received from the children with regard to the question of what can be done to help the environment were enlightening to say the least. Both samples identified that we can help the environment by feeding animals, watering plants, recycling, picking up trash, and planting more trees. These environmentally responsible behaviours were what I had anticipated the children would include in their responses. What I had not anticipated were the creative, more obscure means the children had considered. The urban children demonstrated that they were aware of a multitude of methods of preserving the natural environment. These were not only methods of helping the environment; they were also 
pro-active means to better the situation and to help prevent further damage from occurring. An explanation for this phenomenon is provided by Olofsson, and Öhman, (2006) and van Liere, and Dunlap (1980). They found that urban residents were more likely to be concerned about the environment because they were exposed to more ecological problems. Therefore, the more exposed we are to environmental problems; the more likely we are to be aware of these problems and of the means by which to alleviate them.

Children as environmental advocates: Both rural and urban participants conveyed that they not only felt that things could be done to help the environment, but also expressed that they themselves were capable of doing so. The use of the word 'we' to specify who would be committing the environmentally responsible act, indicates that the children in the study felt a sense of self-efficacy with regard to behaving responsibly towards the environment (i.e., "We can feed them (animals)"; "We shouldn't throw food on the ground...; “...we can plant other things...”; “...we can um... help the trees and plants to survive"). The children exhibited the level of confidence associated with feelings of self-efficacy and, therefore, were aware of the role they play in the protection of the natural environment (Meinhold \& Malkus, 2005). Although both sample groups demonstrated that they were capable of protecting the environment, the urban sample, once again, seemed to have gone one step further. The methods of environmental protection suggested by the urban group were more problem-focused and tended to be more involved. By involved, I mean that it appeared that they visualized themselves completing the actual task they were suggesting. Even though the urban children indicated on several occasions that the actions needed to protect the environment were 
not easy, they never faltered in their devotion to the cause. Statements such as “...it's (protesting animal rights) kind of strange...it doesn't happen very often”; “...I quite need a parent to do that (go on City TV)"...; and “...it's going to be very hard to do it (picking up all the trash)" are indicative of a slight amount of ambivalence among the urban children, but their continued devotion leads me to believe that these hurdles have not put a stop to their environmental efforts.

Kyle, Mowen, and Tarrant (2004) and Kearney (2006) illustrate this increased desire to protect one's own environment as a product of place attachment. The urban children demonstrated a higher level of attachment to their immediate environment, and this could be the reason why they felt more compelled to find ways of preserving it. My findings contradict those of both Cohen (1994) and Kruse and Card (2004), but are somewhat supported by those of Eagles and Demare (1999). The first two studies found that physical proximity and exposure to the natural environment increased the participant's conservation knowledge, their environmental attitudes, their level of animal husbandry, as well as their involvement in environmentally responsible behaviours. As we can see, this is not the case in this particular research study. Like Eagles (1999), proximity and exposure to the natural environment were not necessary for the development of pro-environmental attitudes and behaviours among my urban participants. 


\section{Conclusion}

Children's views of the environment are very different from those of adults, and it is for this reason that it is important to study their experiences independently. To properly capture their understanding of the natural environment, we must put ourselves in their place to see what elements are influential in the development of environmental thought. The particular element of interest in this research study was location, or place of residence. I chose to challenge what Nairn, Panelli, and McCormack (2003) identified as the "myth of rural childhood." This myth declares that children who are brought up in a rural area, in close proximity to natural environment, are much more likely to develop pro-environmental attitudes and behaviours. Nairn et. al. elaborate on this to say that it is in fact not the case, and that the parallels between the rural and urban children in their study do not suggest that there is a universal rural/urban difference in the experience of nature.

In order to determine whether I have successfully challenged this myth, I must first attempt to address the research questions I set to answer at the beginning of this study. The first question I asked was whether urban and rural children differed in their views of the natural environment? Relying on the data collected from my sample, I can say with some confidence that the children shared similar understanding about animal care and the "everyday natural elements." Although there were some similarities, the urban children in this study displayed some major differences when it came to the level of knowledge they had about the environment. The children living in Toronto seemed to have a deeper understanding of the different species of animals in the world, and were more knowledgeable about the different ecological dilemmas we face in today's society. 
The rural children were not as thorough in their description of the state of the environment and instead offered more simplistic, idealistic images of the natural environment. All the children grasped the basic age appropriate needs of wildlife and plant life in the natural environment (Myers Jr., Saunders, \& Garrett, 2004), but noticeable differences between both samples indicate that the urban children view the natural environment in a different way than do the rural children. I find it also important to note that the urban children in this study seemed to mention more of the actual elements of their natural environment than did the rural children. Even though these consisted of man made structures, the urban children spoke of places that they visited or associated with the natural environment in their city, whereas the rural children spoke more of the general parts of the natural environment and not necessarily part of their own immediate environment.

With regard to my second research question about what children in both settings know concerning the preservation of the natural environment, I have found some interesting discrepancies between the sample groups. Both groups listed basic animal/plant needs and picking up litter as means of helping the environment, but it is evident from their responses that the urban children were equipped with more complex and realistic conservation methods. The urban children in my study demonstrated a high level of what Kahn, Jr., and Friedman (1995) call biocentric thought. This thought pattern indicates that the individual considers nature as having intrinsic value and the rights to be protected. As opposed to homocentric thought, where the individual feels that the environment must be protected for the benefit of human welfare, biocentric thinkers have higher tendencies towards environmentally responsible behaviour. An example from the 
interview conducted with $\mathrm{U} 2$ shows this thought pattern. "They (people) don't care about animals, some people just shoot animals for fun um...for instance my Mom's uncle used to shoot things just for fun, just for sport and left them alone and never ate it, or made use of it, and a lot of people do that. It's just horrible!" This child is obviously distressed about the mistreatment and wasteful behaviour that some hunters share, but I do not believe this is because she is worried that there will not be any animals for her to consume later on. She is demonstrating that the animal does not deserve to die in vain and that if it is necessary to kill a living creature, it must be for a valid reason.

Study Limitations: While the present study proved helpful in answering my research questions, I feel that there are a few elements that could have been improved or done differently. The number of participants anticipated for each sample was five in each group. Due to a lack of interest in the communities I attempted to recruit from in Toronto, and a time limitation in which to complete this report, I was unable to recruit the total of five urban children I required for an equal sample. Although this is an ample amount of data with which to support my findings, an equal sample would have been ideal. The difficulties experienced with recruiting urban participants could have limited the representation of urban children in my sample in that I did not have many children interested in my study. It is possible that only the urban children who were enthusiastic about the environment were willing to take part in this study. Other ways that the sample may not have been representative is with regards to parental values and the child's level of self-efficacy. These factors were not isolated in this research, and further analysis would be necessary to establish if any of these elements were influential. 
Other aspects that I eventually would like to explore in future studies are gender and socio-economic status (SES). I am interested in exploring the environmental knowledge present among younger children. It is often assumed that very young children (3-6 years) do not possess the knowledge necessary to form environmental attitudes; I, on the other hand, believe that it may not be the case. The children in my study displayed an incredible amount of knowledge that seemed "beyond their years" and I feel that a more in depth exploration of early childhood environmental knowledge would be required to extinguish these ageist assumptions. SES may have also been influential in the development of environmental knowledge and appreciation among the children in my study. Further research on SES may provide further understanding of how this factor impacts children's environmental experiences.

The joys of working with children were evident throughout this research study. The child centred approach I took with regard to my data collection added a certain aspect of spontaneity to my research. By allowing the children to direct which activity they wanted to complete first (drawing or interview), it reduced the rigidity in which most research studies are conducted, as well as empowering the children in the research process. This approach to research with children requires that the researcher be prepared for almost anything. For example, when I went to visit U4 to collect data, I was happy to have been prepared with a camera feature in my cellular telephone because the child liked his drawing very much and wished to keep it. Since I had a camera handy, I was able to let him keep the drawing without fear of losing that part of his data. Another aspect involved in working with children of different ages is their level of comprehension. In this case, the use of the work environment was not understood by all the children and I 
was often required to use the word nature intermittently with it to help the children understand what I was asking them. Like Littledyke (2004), the children in my study showed different understanding of the word "environment". The younger children seemed to have heard the term used prior to the study, but had difficulty explaining themselves until the word "nature" was used to help further their comprehension of the concept. I very much enjoyed the experiences I shared with the children in this study and feel that if I had used a more quantitative approach to my procedures, that pleasure would have been lost.

The findings and conclusions I have made from the data collected in this study will help to further my understanding of how children in both settings view the environment and what they know about preserving it. The exploration of this topic can be of use in the development of environmental education programs designed to help children in all settings connect with nature. Many programs have been designed to help bring nature home for children, but I feel that we must find nature within their (emphasis mine) homes so that they can best understand the importance of environmental conservation. The need for area-specific environmental education programs is vital so that children may become familiar with the environmental conditions in their own region. This increased awareness of local environmental problems has been found to strengthen environmentally responsible behaviour (Berenguer, 2007; Palmer, Suggate, Robottom, \& Hart, 1999; van Velsor, \& Nilon, 2006). These area specific environmental teaching strategies can also help immigrant children better understand their new surroundings in order to promote pro-environmental attitudes. 
Environmental education programs for rural children may consist of exposing them to local environmental dilemmas so that they may better identify how these are affecting their immediate surroundings. I found that the rural children were not as aware of environmental problems, and by "bringing it home" we may be able to help these children to better understand how it affects them. The phenomenon of "animal aficionados" (Myers, Saunders, \& Garrett, 2004) among the urban children can be encouraged among the rural children by fostering their appreciation for exotic animal species. The urban children in my sample seemed to know more and to be more concerned about animal preservation and protection. If we teach rural children about a wider variety of animal species and expose them to situations where these animals are in danger, they may develop the same sense of advocacy that was demonstrated by the urban children.

For the urban children, these educational programs may involve the inclusion of local animal species in order to help them identify with the wildlife in their own environment. Urban children may also benefit from environmental teachings that include landmarks within their city. Place attachment was found to encourage environmentally responsible behaviour (Kyle, Graefe, Manning, \& Bacon 2004; Kyle, Mowen, \& Tarrent 2004), and if we can help children feel more attached to these man made structures, we may be able to encourage pro-environmental behaviours. Based on my findings, the children living in rural Georgetown and urban Toronto differed in their overall views of the natural environment, and from these conclusions, I feel that area-specific environmental education programs are the next step in helping children better understand the importance of environmental protection and conservation. 


\section{APPENDIX A}

\section{Ryerson University Consent Agreement}

\section{"Urban and Rural Children as Environmental Advocates: The Impact of Location on Environmentally Responsible Behaviour"}

Your child is being asked to participate in a research study. Before you give your consent for your child to be a volunteer, it is important that you read the following information and ask as many questions as necessary to be sure you understand what your child will be asked to do.

\section{Investigator: Sylvie Godin}

Graduate Student, Master of Arts Program in Early Childhood Studies, School of Early Childhood Education, Ryerson University.sgodin@ryerson.ca .

Purpose of the Study: For the purposes of this study, I will be looking at how children who live in an urban or rural setting view their natural environment. I am also interested in looking at how they perceive their abilities to improve the state of the environment through environmentally responsible behaviour.

\section{Description of the Study:}

Two methods of data collection will used in this study. Your child will first be asked to draw a picture and to describe it. Secondly, they will be invited to participate in a one-on one interview which will be recorded for further analysis.

Some sample questions include: "Can you tell me/show me about the environment?" "What kinds of things can we do to help the environment?"

Duration: One hour (approximately)

\section{Study Location:}

The study will either take place in your home, or in an alternative location with which you are comfortable. Parental attendance during the research activities is at the discretion of the child and the parents.

What is Experimental in this Study: The experimental aspect of this study is the gathering of information for the purpose of analysis and theory building.

Risks or Discomforts: It is possible that your child may be uncomfortable or wish to stop, but be unsure of how to say no to the researcher. Therefore, prior to commencing the study, the child will be reminded that he/she can say "no" or "stop now" or "next question." Additionally, the researcher will be alert to non-verbal signs of discomfort and/or fatigue on the part of the child. The topics discussed in this research are not considered to be distressful to the participants but if there is a need for debriefing, the researcher will be available at any time during the study. 
Benefits of the Study: This research will allow me to study the differences between urban and rural children and their views of the natural environment. Your child may benefit from this research by having his/her opinions and ideas validated in the context of a research study. They may also benefit from this information being used to improve methods of teaching children about environmental protection. I cannot guarantee, however, that your child will receive any further benefits from participating in this study.

Confidentiality: Your child will not be identified by their name at any time during this process. Codes will be used to distinguish between the sex and location of each child so that their responses are kept anonymous. The data will be only be shared with my supervisor, and the Oral Evaluation Committee. The final research paper will serve to inform my further studies in this field and may lead to publication. The recorded interviews and your child's drawings will be kept in a secure locked strongbox during the analysis and writing process, as well as for 5 years following the date the data was collected. Should your child wish to review or change the recordings, please feel free to contact me up until August 30 ${ }^{\text {th }}, 2007$.

Incentives to Participate: With your permission, your child will receive a small token of appreciation for completing the study.

Voluntary Nature of Participation: Participation in this study is voluntary. Your child's participation in this study will not influence your future relations with the researcher, or Ryerson University. If you decide that your child may participate, know that you are free to withdraw your consent and to stop their participation at any time without penalty or loss of benefits to which you are allowed.

At any particular point in the study, your child may refuse to answer any particular question or stop participation altogether.

Questions about the Study: If you have any questions about the research now, please ask. If you have questions later about the research, you may contact me or my research supervisor.

Investigator:

Email:

Telephone Number:

Research Supervisor: Robert Rinkoff Ph.D.

Department: Early Childhood Education, Ryerson University

Email: rrinkoff@,ryerson.ca

Telephone Number: (416) 979-5000 ext: 6332

If you have questions regarding your child's rights as a human subject and participant in this study, you may contact the Ryerson University Research Ethics Board for information.

Research Ethics Board

C/o Office of the Vice President, Research and Innovation

Ryerson University

350 Victoria Street

Toronto, ON M5B 2K3

416-979-5042 


\section{Agreement:}

Your signature below indicates that you have read the information in this agreement and have had a chance to ask any questions you have about the study. Your signature also indicates that you agree that your child may participate in the study and have been told that both you and/or your child can change your or his/her mind and withdraw consent to participate at any time. It also signifies that you agree to have the interview tape recorded.

You have been given a copy of this agreement to keep.

You are aware that by signing this consent agreement you are not giving up any of your legal rights.

Name of the child (please print)

$\overline{\text { Age of the child }}$

$\overline{\text { Gender of the child }}$

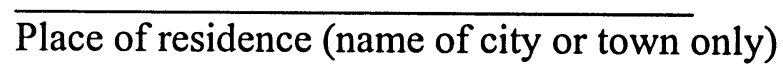

Signature of Parent/Guardian

Date

Signature of Investigator

Date

This signature indicated that you agree to your child being audio recorded for the purposes of this study

Date 


$$
\text { - }
$$




\section{APPENDIX B}

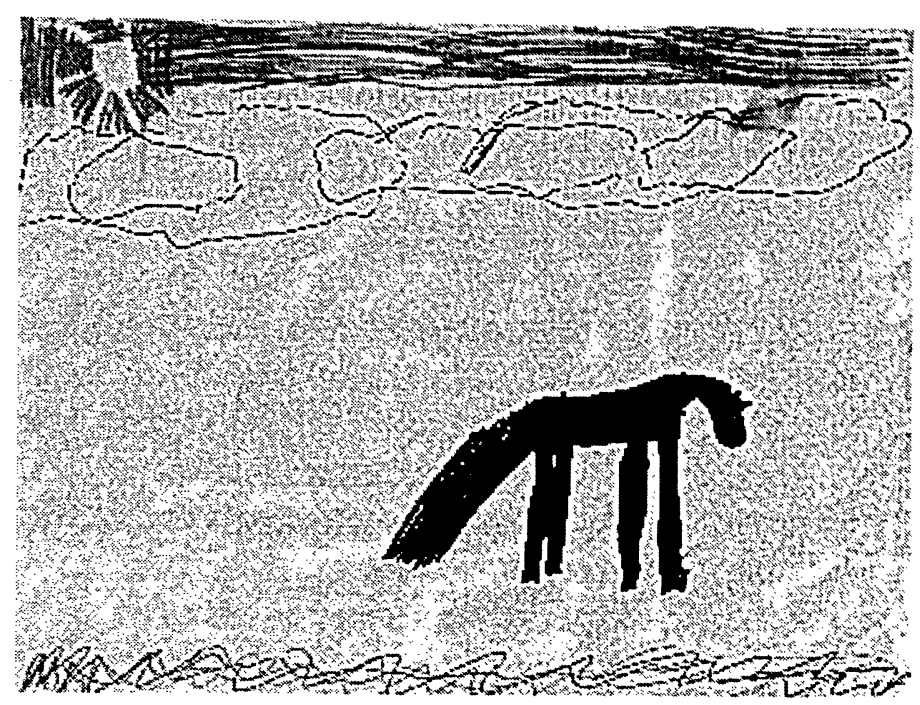

R1 drawing: This drawing is of a black horse grazing in a field of grass with the sky, the sun and clouds over head.

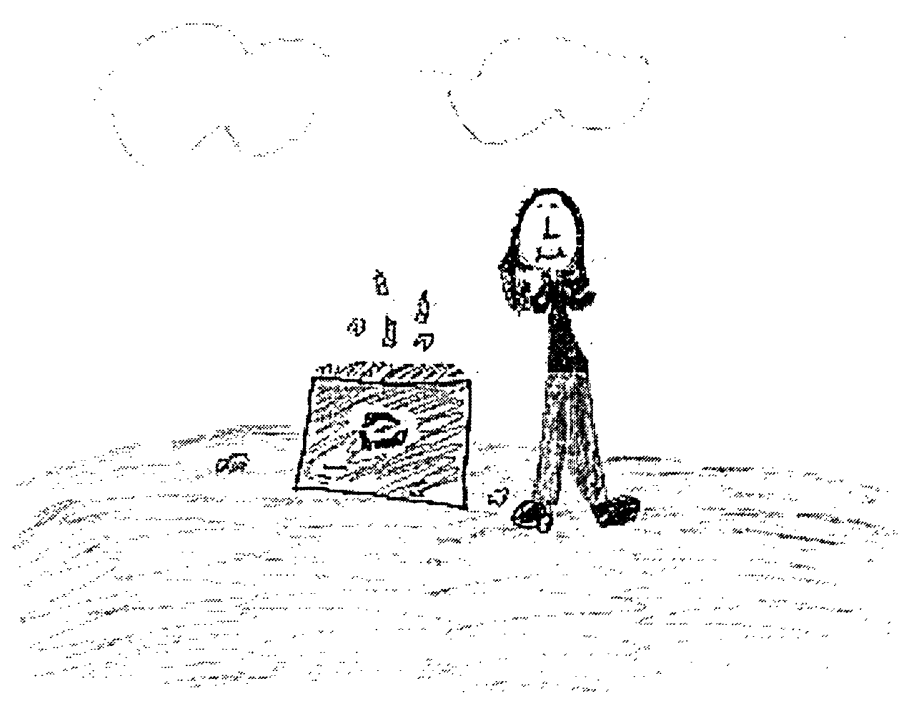

R2 drawing: This child drew herself standing on some grass next to a rec ycling bin. In the drawing, R2 is picking up litter and putting it in the recycling bin. The re are clouds and a sun in the sky. 


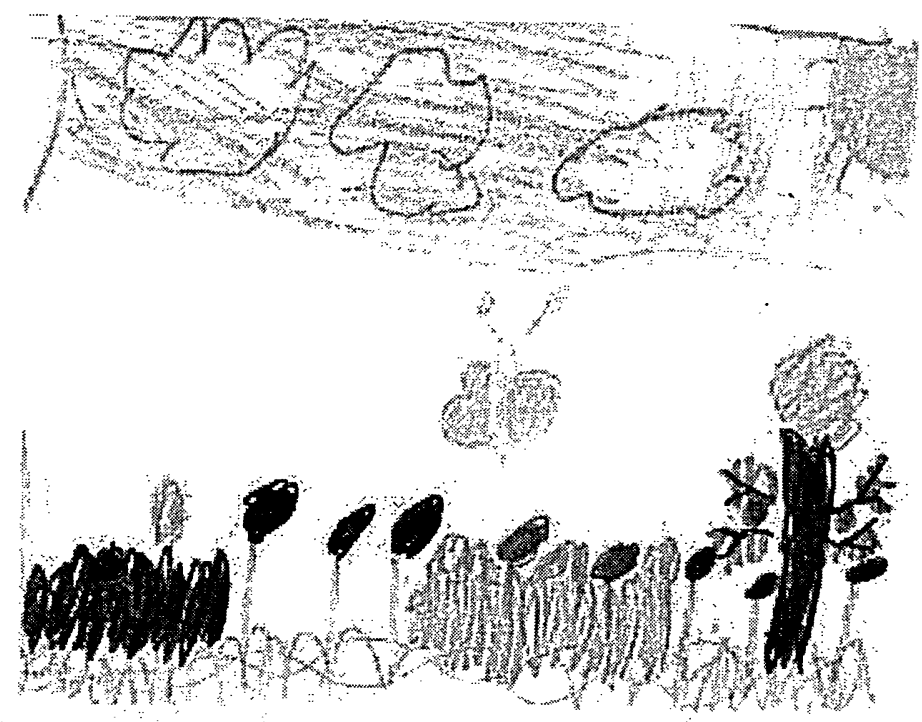

R3 drawing. This is a drawing of a butterfy flying anound in a forest near a pond that has a frog swimming in it. There are also flowers, clouds and the sun.

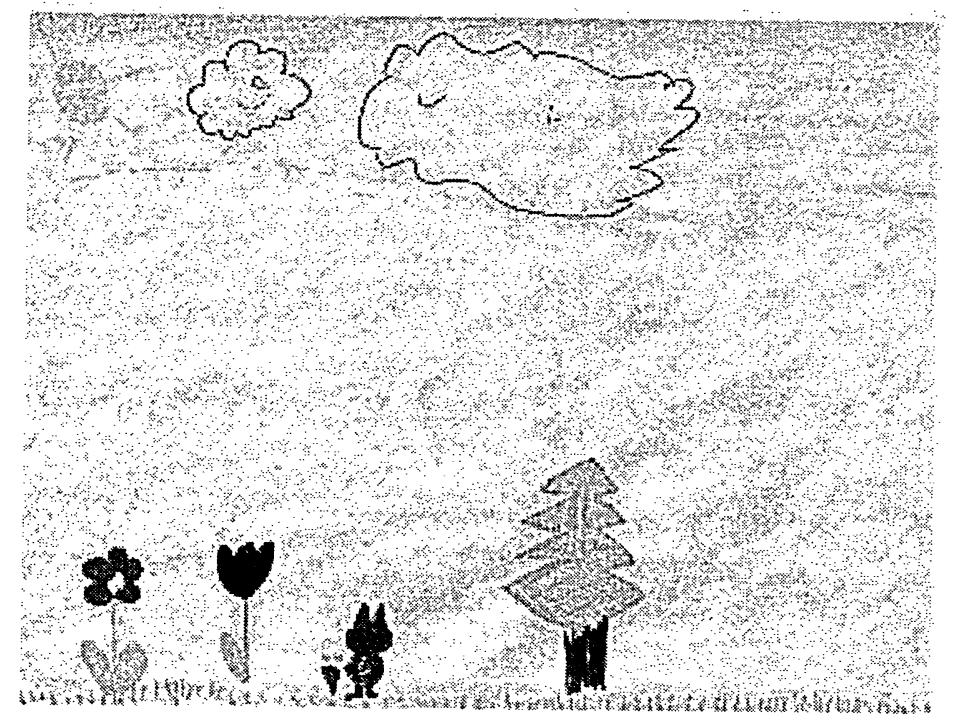

R4 drawing. This is an image of a rabbit holding a carrot standing near two flowers and a pine tree: The re are also clouds and a sun in the sky. 


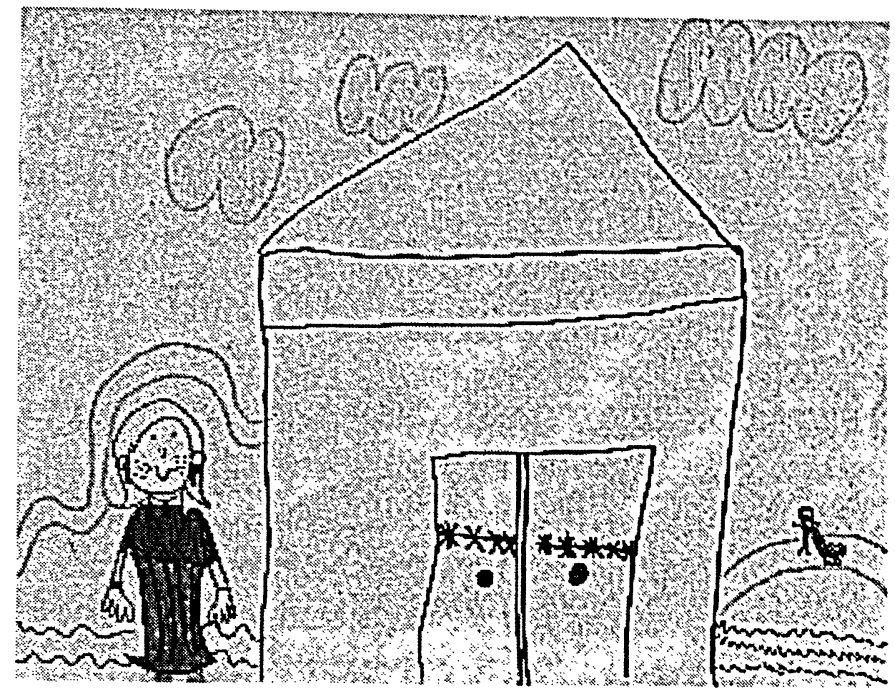

$\mathrm{RS}$ (a) drawing: This child drew a picture of a woman standing next to a school. There is another woman who is walking her dog on a path that runs behind the school. The child also drew clouds in the sky:

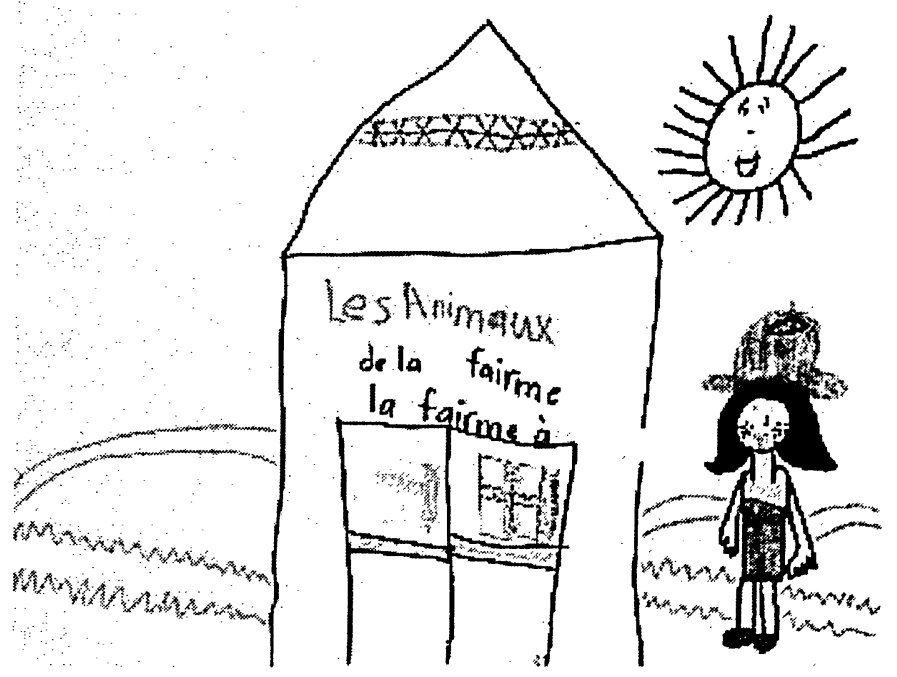

$R 5$ (b) drawing: This is a drawing of $R 5$ wearing a cowboy hat standing next to a farm which she has indicated as her own. She wrote on the bam in French "The animals on (child's name) farm". 


\section{.}

. 


\section{APPENDIX C}

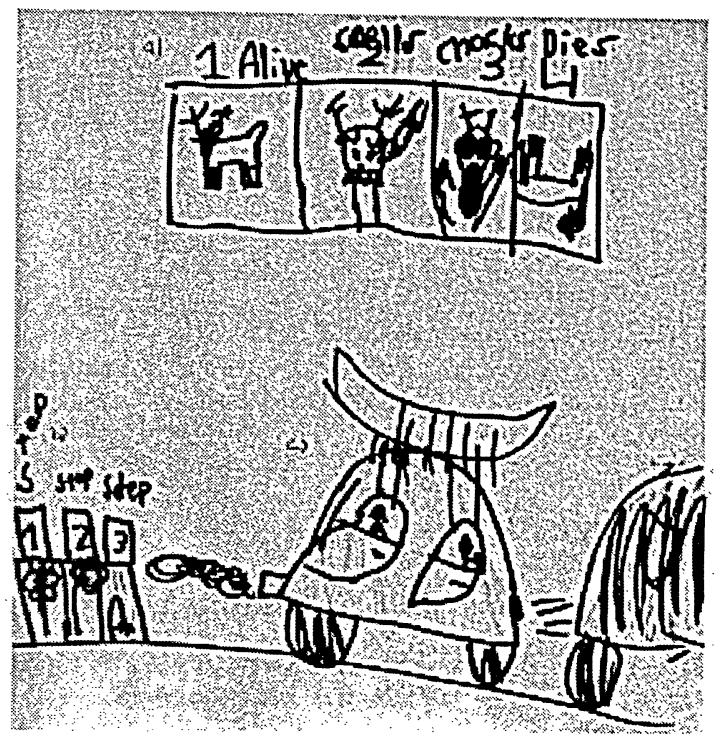

U1 drawing: This drawing has three separate parts. Part a) is a step by step portrayal of a deer dying due to airbome pollution (i.e.: 1 - deer is alive, 2- deer smell pollution, 3- deer chokes, and 4 deer dies. Part b) is also a ste pby step demonstration of the same effect of airbome pollution, but on a single flower (i.e.: 1- flower is alive, 2-flower is ex posed to pollution, and 3-flower dies. Part c) of this drawing is of two cars, one with a canoe on the roof. These people are driving their cars to

Flonda for a vacation. One of the cars is shown to be emitting exhaust pollution from the tail pipe.

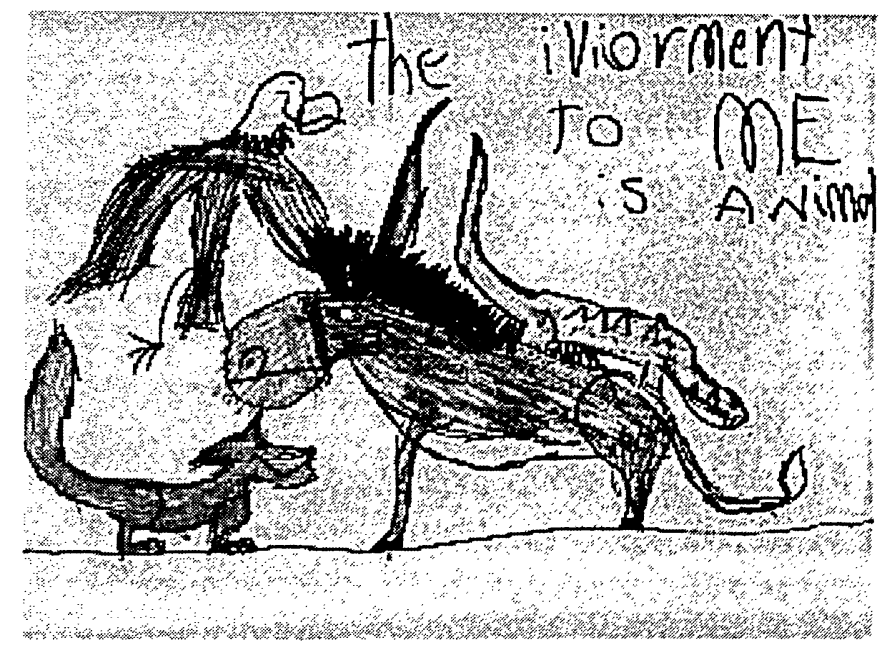

U2 drawing: This drawing is of a meeting between a donkey, an alligator, a fox and an eagle. They are mee ting to discuss the proble m of animals wanting to stick to their own kind. U2 has titled this drawing "The iviorment(sic) to me is animals". 


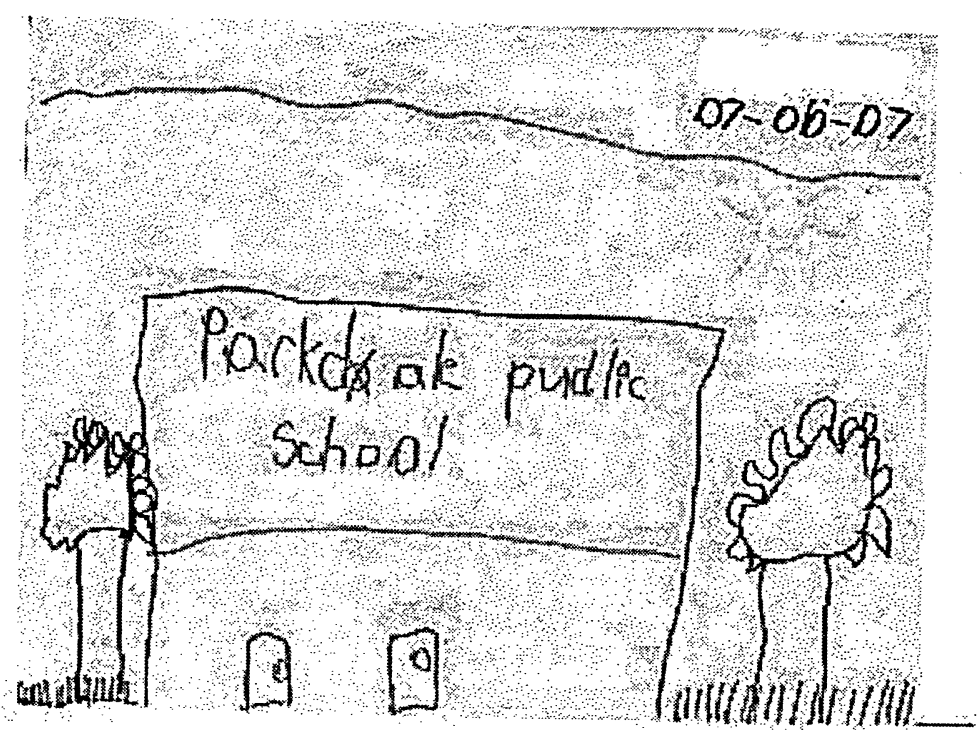

U3 drawing. This child drew the school that he attends along with the sky, the sum and two trees with leaves growing beside the school A line was added to divide the school in two because the child indicated that the ir classroom was on the second floor.

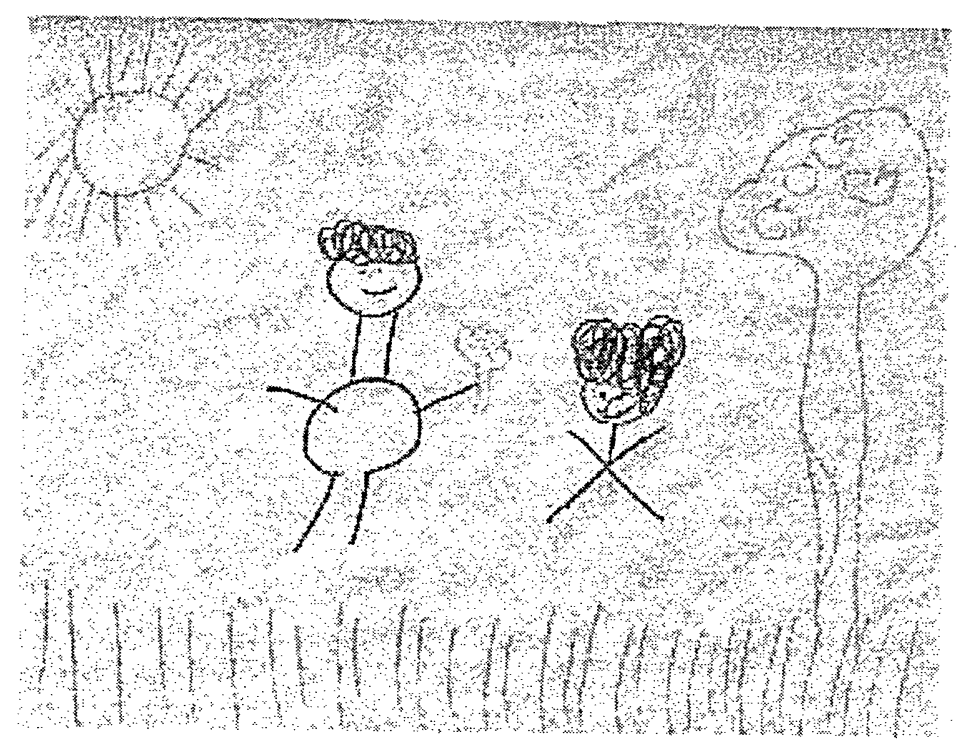

U4 drawing: This is a researcher re plica of the portrait drawn by U4. The child drew himself with his older brother standing under the sun beside an apple tree. There is also a smaller apple tree in the background meant to indicate that it is far away. (The child wanted to keep the onginal drawing) 


\section{APPENDIX D}

\section{Transcript for R1}

Hello (child's name). Okay, talk to me about the environment. Do you know what the environment is?

R1: (Shakes her head to demonstrate no)

No, you don't know what the environment is? Do you know what nature is?

R1: (Nods her head to demonstrate yes)

Can you tell me what it is? What do you think about nature? What does it make you think of?

R1: I don't know...birds.

Birds? What else?

\section{R1: Trees}

What do you think about nature?

R1: (Shrugs her shoulders)

That's okay, is there anything that you like or dislike about the environment?

Father: If you don't say anything, they won't here you.

That's fine, do you want to think about it?

Father: There's no wrong answer, she just wants to know what you think about it.

Yep, I just want to know how you feel.

Okay, of everything in nature, animals, trees...is there anything you don't like

R1: (Shakes her head to demonstrate no)

Do you know of anything we can do to help nature?

R1: (Shrugs her shoulders)

What is your favourite thing to do in nature? What sorts of things do you do in nature?

R1: (Shrugs her shoulders)

When you think of animals and trees, are there things that you can do to help them?

R1: We can feed them

Yes, feed them. What else can we do for plants, trees, and animals?

R1: Give them water

Water, yes

When you think of nature, how do you feel? When you look outside, what do you think?

R1: (Shrugs her shoulders)

Are you done? Do you want to draw a picture for me now?

$\mathrm{R} 1$ : (nods to indicate yes) 


\section{Transcript for R2}

Hello, today is June $13^{\text {th }}$.

Do you know what the environment is? What I say the environment, what do you think?

R2: It's recycling

Okay, what is recycling? Why do we do it? What does it have to do with then environment?

R2: It helps the earth, so there is not so much trash, because if so, it will be very hot in the future and yes.

What sorts of things do we do to the environment that will make it hot? I know that you mentioned that if we don't recycling, but what other things do we do that make it hotter? Are there other things that we should be doing?

R2: We shouldn't throw food on the ground and trash and we should stop using plastic and put it in the recycling. We should reuse stuff instead of putting it in a big pile of trash.

Is there anything aside from recycling that we can do to help them environment? You said that we can reuse things, but are there any other things that we can do?

R2: We can, if we see trash on the ground, pick it up.

Anything else?

R2: That's it.

That't is? Great, I just wanted to know if you could think of anything else. Do you feel that you are capable of helping the environment? Can you make a difference?

R2: Yes

You feel that as a child, you can help the environment?

R2: Yep

Yep? Is there anything that you don't like about the environment? Or that you do like?

R2: One thing that I really don't like is when there is trash on the ground because it makes me feel that the earth is going to be rotten and full of trash. Yeah.

Is there something that you like about the environment? That you like a lot? There can be more than one thing if you like.

R2: I like nature, I like it when it is all clean and I like to recycle yep.

Is that is?

R2: Yes

Is there anything else you would like to add about the environment, anything at all?

(pause)

R2: Um...that's all I can think of.

That's great! I just wanted to give the chance to add something in case you wanted to.

\section{Transcript for R3}

Today is June $13^{\text {th }}$

Do you know what the environment is? Nature, what is nature?

R3: Rabbits, forests, flowers, trees, grass, fish, water, dirt...We go outside to get air and stuff like that. 
Are there other things? When I say the environment now, do you understand what it is?

R3: yes

When we talk about the environment, are there things that we can do to help the environment?

R3: um, yes, we can plant other things, we can um...I forgot.

That's okay, so we can plant things to help the environment. Is there anything else you can think of?

R3: No

No? okay, Is there anything that you like about the environment? That you like a lot?

R3: um...forests.

Forests? What about forests do you like? Why do you like them?

R3: Um...there are trees, animals, and leaves and this is where my grandfather, when he comes to visits us, we always go to a tree um, and after...(inaudible)... construction.

Construction?

R3: Yes

Are there things that you don't like in the environment?

R3: No

There is nothing you don't like in the environment?

Are there other things that you can tell me about the environment?

R3: (Shakes head to indicate no) How do you feel when you think of the environment? When you go to the forest with your grandfather,
how do you feel?

R3: um...proud.

Why do you feel proud? What makes you feel proud?

R3: Because we go a lot and ...(inaudible) and he tells me that we are going to go there .

What do you do there? What do you do in the forest together?

R3: We just walk in the forest, and then we stop and he shows me things.

He shows you things when you go for a walk in the forest? Is there anything else that you would like to add or is that all?

R3: Yes

That's it? Okay, thanks.

\section{Transcript for R4}

June $13^{\text {th }}$ with $\mathrm{R} 4$

Do you know what the environment is?

R4: (Shakes head to indicate no)

The environment, you don't know what it is? Do you know what nature is? When I say nature, what do you think?

R4: Um...it's like um... I don't know how to explain it.

Can you tell me the things you think of when you think of nature? 
R4: Um...like it makes me think of outside.

What about outside?

R4: Um...trees, the sky, lots of things outside.

Can you think of other things that are outside?

R4: Um...grass...asphalt...

Is there more? So you said outside there are trees and grass, but what else is there outside?

R4: Air

Is there anything else...in the sky or in the trees that you can think of?

(pause)

R4: Houses, the sun and clouds.

When you think of the environment or nature, how do you feel?

(pause)

Do you understand what I am asking you?

(Shakes head to indicate no)

Like when you see trees, or the air or the sun...how do you feel? Do those things make you think of anything?

R4: No

That's okay. Do you think that there are things that we can do to help nature, to help the things that you just mentioned?

R4: Yes

Yes? What sorts of things?

Like if there is trash, we can pick it up.

(pause)

Are there other things?

R4: We can plant more plants and we can water the plants.

Is there more we can do to help?

(pause)

R4: I don't know.

Okay, when I talk about the environment or nature, are there things that you like in it?

R4: The sun because it keeps me warm.

Is there something else that you like?

R4: Air and plants

Why do you like plants?

R4: Because they are beautiful.

Anything else that you like?

R4: the grass

Are there things that you don't like in the environment? 


\section{R4: Clouds}

Why don't you like clouds?

R4: Because it can rain.

Anything else you don't like?

R4: No

Is there anything else you can tell me about the environment? Is there anything you want to add now that
we have talked about it?

R4: No

Okay, thank you.

\section{Transcript for R5}

Do you know what the environment is?

R5: (Shakes head to indicate no)

Do you know what nature is?

\section{R5: Yes}

What is nature? Tell me about it.

R5: It's like snow, the sun, trees, the air, lots of wind.

Are there other things in nature?

R5: Plants, there are (inaudible) and schools.

Pardon me? There are countries?

R5: (Nods head to indicate yes)

Are there other things in nature or the environment? Do you understand now what I mean by environment?

R5: (Nods head to indicate yes)

It's almost the same as nature. Are there other things about nature that you want to talk about? You said that there is snow, the sun, trees, air, wind, plants, countries and schools, is there anything else?

R5: Trees, animals, people, leaves, sidewalks, stores, there are parents, there are fruit, food.

What kinds of food?

R5: All kinds of food.

Is there anything else?

R5: There are rules

What kind of rules are there in the environment?

R5: Like not touching things, because they are dangerous. Things can cut you.

Is there anything else that is dangerous in the environment?

R5: Glass

What else?

R5: If you fall, you can break bones.

Anything else? 
R5: There are kids, cars, speeding, houses, hotels, places where people pay like in stores, toys, and numbers.

So there are a lot of things in the environment? Is there anything we can do to help nature?

R5: Maybe we can help people.

How can we help people?

R5: You can say something to them if do something to you.

Is there anything else we can do to help nature? You said there are stores, and trees. Is there something that we can do to help these things?

R5: You can help them when they get hurt.

When people get hurt you can help them?

R5: When they fall.

Are there other ways we fan help nature?

R5: um...no...

That's okay. Are there things that you don't like in nature?

R5: Snakes, I don't like spiders.

Is there anything else that you don't like?

R5: I like frogs!

Well, I was going to ask you what you liked, so you like frogs?

R5: Yes but I don't like when they ....I had a frog at my house and when my mom fed it um...her finger was near his mouth and after just "just crunch!"

It bit her finger? So you like frogs, but not when they bite your finger?

R5: My mother's finger

Your mother's finger, what she alright?

R5: Yes

They don't have teeth, but I'm sure it hurt.

R5: Now it's in a store, but it's not for sale.

No?

R5: They are just keeping it for me.

So it's in an aquarium so that people can look at it?

R5: Yes

Is there anything else that you like or don't like?

R5: I like frogs when they hop and I like countries. They are a lot of fun.

What countries have you visited?

R5: I've been to a Chinese place.

China? Japan?

R5: No, my father has been there for work.

So your father had been to China, but you haven't? 
R5: No, but I went to a place in China, but they all spoke English there.

Is there anything else that you like?

R5: I like countries when they are hot.

You like countries that are hot?

R5: Yes, and parties because my birthday is in June.

June? When is your birthday?

R5: June $20^{\text {th }}$.

Wow! My birthday is on June $28^{\text {th }}$. Yours is close to mine!

Anything else you like?

R5: I like dolls, I like pretty dolls. I have a doll room. 



\section{APPENDIX E}

\section{Transcript for U1}

Okay, were here with Finkle Tinkle (child's chosen pseudoname)

What does the environment mean to you?

U1: Well, plants, and animals, and um...people, and the world, and uhmmmm...(pause) flowers and that's
about it!

Okay, what do you like about the environment? We will start with that one.

U1: That's tough

Why is it tough?

U1: I don't know...

You don't know why it's tough?

U1: Well...ummm....hard...um...

What sorts of things do you like to see, or like to visit or something?

U1: Umm.... The zoo.

The zoo? Is that what you like about the environment? What about the zoo...

U1: Yep..ummm (pause)

Its okay, you don't have to tell me what you like.

U1: um...

Amongst the things that you said earlier, in all the things you listed off as part of the environment, which of those do you like? You said plants, animals, people, the world, and flowers. What among those things do you like?

\section{U1: Animals!}

What do you like about animals?

U1: Well, they are cute.

What else about them?

U1: And fuzzy, and some aren't fuzzy.

Some of them aren't. Do you like then even though they are not fuzzy?

U1: Yeah, I don't care their shape or size. It doesn't matter to me. I like animals and bugs.

They're all part of the same, they're insects. But when you say animals, I understand that you mean bugs too. So, what sorts of things don't you like about the environment?

\section{U1: POACHERS!}

Poachers? What are poachers?

U1: Well they are basically hunters that hurt really really rare animals like cheetahs, elephants...you know. Why don't you like them?

U1: Cause you know, there killing animals and if they keep it up we're not going to have any animals left. But their obviously not... (Inaudible)

What about that don't you like? 


\section{U1: What do you mean?}

Like okay, you say that if they keep killing them there will be no animals left right?

U1: un hun.

What do you not like about that? I sit because they are killing them, or is it because there's not going to be any left or both?

U1: It's just killing them....um... yeah both.

You're unhappy with poachers in general. You just think..okay.

U1: Poachers are mean.

\section{There mean? Mean because?}

U1: They're hunting animals and it's not nice, and they made it, I mean God made nature and they shouldn't be hunting them.

Okay, what sorts of things can we do to help the environment?

U1: Um...well...(pause)

Like are there things we can do?

U1: Um... maybe the first thing is to stop poaching...well...this is a hard one.

That's okay. So to help the environment we can stop poaching. What other ways can we help the environment?

U1: um... stop littering.

Stop littering?

(Tape stopped and turned over)

So we were saying that to stop littering would be one thing that we could do to help the environment, is what you said. Why would not littering help the environment?

U1: Well because....

Because?..

U1: well...

You said that to help the environment we should stop littering but why would littering not be helping?

U1: Well the pollution basically. It's killing everything!

So is there anything else we can do to help the environment? Did you want me to remind you of what you said were part of the environment?

U1: Wait! You know those engines that are on cars that have gas things on them.

Exhaust?

U1: Yeah!

The stuff that comes out cars, that's called exhaust. The car burns the gas and the oil and pumps that out...

U1: Yeah, that's kind of pollution!

Yes it is pollution. So how can you help them environment in regards to that?

U1: Stop um...using cars like that and go to cars like...I don't know... what are cars that don't um....that stuff...um...

Do you want to explain further what you are trying to say?

U1: um..... (pause) 
You said to stop using cars, instead using...

U1: Cars that don't have exhaustion!

Cars that don't have exhaust?

U1: Yeah!

Do you know of any kinds of cars that they make like that?

U1: I can't remember what they're called.

But you know of cars out there that don't use...

U1: Yeah.

Okay, that's okay, it's enough.

U1: Are there any cars that run on batteries?

Well, cars already use batteries, but they use gas as well. But there are lots of cars out there that don't use gas. There are cars that use water, some use electricity, and some use a little bit of gas and a little bit of electricity. They are trying to make cars that pollute less, is that what you were trying to say?

U1: Yeah

Is there anything else that you want to say?

U1: Ummm..... no

Nothing else? So we've got a lot of information here, lots about poachers right? And you think that to help the environment we should stop poaching and stop littering because pollution is killing everything and you also said that we should stop using cars that have exhaust right? They use exhaust and we should use cars that have different (inaudible) is that everything?

U1: Yep.

Thanks!

\section{Transcript for U2}

Tell me about the environment, what is the environment to you? When I say environment, what do you think?

U2: I think um...it's very busy and confusing at times.

What is busy and confusing about the environment?

U2: Um.....What do you mean?

Well, when I asked you what you think of the environment, what do you think of? You said it was busy and confusing, what makes it like that?

U2: Um...sometimes there's things that I don't understand like. Um...why you're parents aren't letting you go somewhere like someplace and you don't understand why they're not letting you go.

Okay

U2: It's busy because there are lots of people around, like there's tones of people around here and it's really busy all the time. Like every town is busy, every city is busy... well Huntsville isn't really busy but...

Why is that?...um..Okay. What other things are part of the environment?

U2: Um...trees, plants, animals, human mortals...

Human mortals?

U2: What? 
I just wanted to make sure that's what you said.

U2: Yeah. It's about everything, like matter is everything in the whole world is matter. That's because it's everything.

What does that have to do with the environment?

U2: Um... What do you mean?

Cause you said that everything is matter but that is in the environment right?

U2: Yeah

I just wanted to understand why, so if everything is matter, what is that in the environment?

U2: Um....it actually is part of the environment.

Okay so...

U2: Cause it...

I don't understand...

U2: Matter itself

Okay, so you're saying that the environment is part of the matter that is everything.

U2: Yes

Okay, I just wanted to make sure that I understand what you're saying.

U2: There's two, I mean matter that is everything and everything that matters like um....like it should be treated well. Sometimes animals are treated well, like in zoos like the Toronto Zoo and some things are horribly treated like in little tiny zoos like in Romania or some place like that. And plants should definitely be treated better, cause I see a lot of people, like at the Toronto Zoo there's this headquarters place where there's all kinds of animal furs that people are like taking and weird kinds of plants. They take the plants and the animals and they try to make like slippers out of the animals, I mean... What are they thinking?

Un hun...Well the next questions kind of plays on that. So um... you have already answered that, but I was going to ask you what sorts of things do you like about the environment, and what sorts of that you do not like about the environment?

U2: (Inaudible)

Do you want to start with what you like?

U2: Yeah

Okay, what do you like about the environment?

U2: I like things that are exotic and new that you figure out every time you do something. Like every time you go to the zoo, you figure out something new. Like every time you go...(Inaudible) There's a lot of things that I do like and don't.

Okay

U2: And another one of them that I don't like

You don't like?

U2: Is definitely littering

Littering? Okay what about littering that you don't like?

U2: That the...that it doesn't make the environment look as pretty like when they do graffiti on brick walls and graffiti on boats if that's even possible and I think things that you're driving in like, what are those things called? Things that you go underground in...like the subway.

Are you talking about the subway train?

U2: Yeah, sometimes there's graffiti on them. 
On the train?

U2: Yeah

Yeah, there's sometimes there's graffiti on the subway train.

U2: Yeah I hate it!

Why do you hate it?

U2: Cause' (inaudible)

Sorry, what did you say?

U2: (inaudible). It's just not right!

It's not right, but why is it not right?

U2: Because it is making things look horrible and there supposed to look beautiful. Like um...like houses and fences and that's still wood and still looks pretty like the design of some sort on it and then there's graffiti written all over it. That's horrible and...

What else do you not like?

U2: When people leave things. If they break something, like a tree or something and they break something in a store they just leave it cause' because they don't care. It's the same thing as animals. They don't care about animals, some people just shoot animals for fun um...for instance my Mom's uncle used to shoot things just for fun, just for sport and left them alone and never ate it, or made use of it, and a lot of people
do that. It's just horrible.

Okay, what sorts of things can you do to help the environment?

U2: Well, there's this commercial on TV and it's about helping animals and plants and exotic things.

Un hun...

U2: and I think, like you have to donate money, so people can like make sure it doesn't happen very often, and that's what I'm going to do...I told my Mom already

Okay, is there anything else that you can do to stop those things that you don't like?

U2: Well, littering, I could probably pick up litter and things at my school, there's a lot of garbage on the floor, like there's these things we have at pizza day and we have chips outside and pizza and they litter their napkins and things and the teachers keep saying "Don't litter. Don't litter!"and they do and I have to pick it up. One time...(inaudible)...

Is there anything else you can think about that you can do to help the environment?

U2: ... another way is to do something really strange which I probably wouldn't do um... is to get a whole bunch of animal lovers or stuff...people who like animals and plants and wave signs and go around walking the streets with a sign in their hand saying "Do not litter, do no litter!" That would be freaky...

Why is that freaky?

U2: Well, it's kind of strange with people walking around with signs saying "Don't litter, don't litter, don't litter!"

Why is that strange?

U2: Well, it doesn't happen very often. I don't see that. I've probably only seen it once every ten years...I've only been living for eight years um... (inaudible)

Okay, so I think what you are describing to me is called demonstration, or protesting. Is that the word you are looking for?

U2: Yeah.

Okay, so you said that it doesn't often happen, is that what you are saying?

U2: Yeah, you know what I don't like?

So why...sorry, what don't you like? Sorry, carry on. 
U2: Um...there's these things that these two boys were doing. They were on the streets and they were making people give them their money for drugs, to buy drugs.

That's not good.

U2: No... (inaudible)

Sorry?

U2: What are drugs made of anyways?

Lot's of different things.

U2: Like plants or something?

Some have plants, some have chemicals.

U2: I don't like how they take plants and make it into something you shouldn't use. That's what I really don't like. There are a lot of bad things in the universe.

Un hun...

U2: Is it raining outside?

No, it's the sprinkler, probably watering the grass. Okay um...is there anything that everybody can do to help the environment? I know that you said all these things that you can do, but is there anything that other people can do?

U2: A lot of people can join together and not just have, they shouldn't just clean garbage on garbage day, and um... The day that happens like only one time, not every Friday or garbage day, um and people just pick up things from the ground. I think that we should not do that just on the day of garbage day but do it everyday and not just one day of the month.

Anything else?

U2: No, I think that's about it...my noggin is all gone!

Anything else you want to add about the environment?

U2: Nope

Thank you very much

U2: You're welcome very much.

\section{Transcript for U3}

Today is July $6^{\text {th }}$ with U3

Can you tell me about the environment?

U3: Well...I've been thinking to be going on CITY TV to stop telling them to stop throwing their stuff on the ground because ants and bugs can't eat that stuff like plastic water bottle or all that...but they they can only eat apple craps, banana peels ....all that stuff, but that's what the environment... it makes Mother Nature hard to clean all that stuff up so please don't do that because Mother Nature won't like that! And it make sit hard for her to do it and and bugs can't eat that stuff that's true!

Un hun.... So did you say that you want to go on City TV and tell them to tell people to stop doing that? U3: Yeah

How are you going to do that?

U3: Um... well I quite need a parent to do that or my um cousins who are bigger than me but they live in the United States so they can't come and (inaudible)...to Canada because that's too far for them

Un hun.. 

U3: ...but they do live in North America....and there's two languages we speak in Canada that's English
and French.

Do you speak both languages?

U3: No...I only speak English, but my Grandma knows a lot of French, but my Mom knows a little.

I speak French too!

U3: (inaudible)... and that kid over there on the other side, my neighbour Cathy ...his name is Liam.

Yeah?

U3: Yeah, he's only 4 four years old and almost my birthday is coming up.

Really?

U3: It's July $21^{\text {st }}$

Well happy birthday in advance because I probably won't see you that day. Is there anything else you want to tell me about the environment? I know you talked about how you want to go on City TV and tell them to stop littering because the bugs can't eat the litter, right?

U3: Yeah

Is there anything else?

U3: Not quite

That you can tell me about the environment?

U3: Yes... but I know some stuff about the universe and the solar system.

Okay

U3: Can I tell you about some about that?

Of course

U3: Okay so Mercury is the planet closest to the sun and it's the first planet and it reaches 800 degrees Fahrenheit...and Mercury is named after the Roman god of speed. Venus the second planet from the sun is the brightest planet in our sky and it's named after the Roman god of love and beauty.

Unhun...

U3: Un hun...Earth is the third planet from the sun that's the planet people live on and (inaudible) excuse me for one minute. Peter, can you go play with Liam? Mars...I mean... I'm still on earth right? Earth is um the old English god it means something like that. Mars is the forth planet from the sun it is Red because it has rust on it, Mars s named after the Roman god of war because it's red blood colour. Jupiter is the fifth planet from the sun is the biggest planet, it has the great red spot, it's a wind storm and it's named after the Roam god it's the King it was the Kind...Then Saturn the sixth planet from the sun it has rings and it I can't remember what god it's named after because the A word is too hard for me..(inaudible) but I have a white tiger in my group like it's from another other other long word like different or those hard words I have to go to my agenda. I use that to help me spell words I can't remember how to spell in school.

Un hun.

U3: So let's just skip Saturn and go on to Uranus. Uranus is the seventh planet from the sun and it rotates on it's side and and it has 18 moons I guess, 18 and Neptune the eighth planet from the sun and it Neptune has eight moons and it's named after the Roman god of Oceans and the last planet of course Pluto. Pluto the ninth planet from the sun. Pluto is named after the Roman god of the underworld and it's the furthest planet from the sun... and it was discovered in 1930 by Clyde William Tombac... I think his name is oh and can you go back to Earth because I just want to change how it came. It was discovered in the $16^{\text {th }}$ century by a Polish astronomer named Nicholas Copernicus and he's favourite astronomy, his card is up there. And I can use them and I can find Nicholas Copernicus I know him.. my Mom has studied him, I wasn't born in $16^{\text {th }}$ century and I don't know when he died. Okay that's all I know about the solar system but I know something between Mars and Jupiter there's the asteroid belt. The asteroid belt is definitely orbits the sun and there's another thing about Earth. It takes I think 800 24hour to rotate on it's axis and Earth takes 2062, I think, I don't know what this is, but I have it my leap pad, I have 2 of them one is Spider man and one is just a plain old one that I got. So... so is there another question?

Oh yes. Okay, so you've talked about the environment. Do you know what nature is? 
U3: Uhhh....I think no...but there, I know that there's a small forest near the Beer Store but me and my Dad go through it and I see all of nature. Trees, leaves, grass, a path, hopefully a path, if I see and, and I see the train tracks like the Go trains and the other trains that run on those tracks and I know about the stations. TTC stations. I can say from Kipling to about Woodborn.

Wow

U3: I can say that.

Wow, you know a lot about the TTC stations.

U3: Un hun.. I've ridden on them lots of time with my Mom and Dad.

Yeah? Okay, so you said that you see nature around here, right?

U3: Yeah.

So when I say nature and the environment, are those the same thing?

U3: No

No? There two different things?

U3: Yeah, two different.

Can you tell me the difference between the two?

U3: Yeah, they're different because...because the nature is something else with leaves trees all that. And, and, and ... the second thing... what's it called again?

The environment

U3: The environment it' something else when ants chew on something that is not good for then to eat cause' it can make them sick and die.

Can you say that again? Sorry, the environment is things that ants eat that makes them sick and die? Is that what you said?

U3: Yeah

So, so it's the environment, then things that ants eat that makes them sick?

U3: No

So what's the environment? I just want to understand what you're saying.

U3: It's the ...the environment is um...um... when you throw something out on the um...on the...on the street and and when ants chew it up its makes then a little bit sick, but they're not allowed to eat plastic and all that stuff. They're only allowed to eat apple scraps, banana peels, watermelon seeds if they're dark (inaudible)... and the apple whose, the things that come out of the apples, they can eat that too......un hun....and there's something else I know.

What's that?

U3: Animals!

What about animals?

U3: Okay, the first animal I'm going to start with is... the tiger. Their main enemy is us. The humans, that's what we are. Then their location is Asia, definitely Asia. Okay...

Can I ask you a question about that before we go on?

U3: Yeah

You said that humans are the tiger's worst biggest enemy; can you explain more of that to me please?

U3: Yeah, it's their main enemy and their orange and black. I've never seen a real tiger before, but you can see them at zoos. Like lions.

But why are humans their enemies? What makes us their enemies? 
U3: Um... because we try to, man, that's 100 years ago, there used to be troops with these animals. With like wild animals and dogs, um um and there's another type of dog, it's called the hyena. It's another type of dog and I think its world wide. And hyenas has, they go in troops large troops I guess and they can never come to North America because they say it's cold that's why they, that's why they cannot come to Canada and the United States.

Un hun.

U3: Alright, the next, the next one is called to Komodo dragon. It has deadly bacteria in its mouth that's true and when it bites you, you could die that's really true but do you know what I say to my family, like my Dad or Mom, I say, let's not go to where Komodo dragons live. Cause' they may bite us and they could die. So that's why I tell them to stay in to, stay into North American and there's two kinds of vampire bats. The first vampire bat lives next one down from North America, South America. And they say that they they suck blood from livestock.

Un hun...

U3: And there's another kind. That kind of bat is a vampire bat that lives in Africa, tropical Africa.

(The tape ended in the middle of this statement and was not corrected until after the response was completed.)

U3 continuation... Okay, so what is it about the environment or nature that you don't like?

U3: (inaudible) I don't like when ants chew on plastic, it could make them sick. That's what I don't like, and there's another thing and it's different in nature. It makes it hard for Mother Nature to do all the stuff of when people litter, never ever I litter cause' I know what to do. And and I have went on a school trip before, it was up at Don Mills at the Ontario Science Centre. And we went to a place at the Ontario Science Centre that have this cave and you go up on this cave and there's goggles on it and you can see stuff all round the Ontario Science Centre. They have (inaudible and father speaking).

U3: And when I saw that, saw some stuff and (inaudible) It was so cool! And they have this place in the cave that (inaudible). That's Tristan's Mom, and then there were 6 people in it. There was me, my partner Steven, Abigail, Sharika, Tristan and he was partners with his Mom, okay so that's was 6 people. And we had another three, it was (inaudible). Okay so, okay that's and it makes it hard for Mother Nature to do all that stuff when people do litter, or sometimes I never litter or (inaudible) cause' they do not sometimes they eat but they don't litter cause' they're not in packages

Un hun... So what you don't like about the environment is that how ants chew on plastic and the plastic gets there because people litter it?

U3: Yeah

And that's what you don't like, you don't like when people litter?

U3: Un hun

Because, you don't like it because it's hard for Mother Nature to keep things clean.

U3: Yeah

Is that what you said? I just want to make sure that I understand.

U3: Yeah.

Okay, um...the next question that I want to ask you is, do you know of anything that we can do to help nature, or to help the environment?

U3: I know... (inaudible) trash cleaning and pick all that stuff up, but it's going to be very hard to do it, I know, because people throw it and the people who throw it, they have to clean it up. And when they're in taxis or cars... when they drive the cars and when they're smoking cigarettes, this is what they do. They just throw it out of the window on the highways, my dad did that one time when we had to go to a job site at Lakeshore Blvd and Park...(inaudible)...

So, things that we can do to help the environment is to clean up the trash?

U3: Yeah

Is there anything else we can do?

U3: Yeah, you can start your own nature club. 
Start a nature club? Can you tell me about that?

U3: Okay, I was going to do that in school but, but I had already made a club with my friend Sam, he was in my class. We, we, we called it the listening club. We got some people in it, we got Tristan, one of my classmates, it's me, uh.. Sam, he helped me did it, and Dylan , and Sam's friend David. I, I ooh and I think one, this big kid wanted to get in and we played king zombie tag, he was it and if when the zombie King touches you, or a person who is already a zombie um...that means when you, when the person touches you, you have to go and get that person. And we got another person in and his name is Jamal. He was one of my friends and he tried his best to listen and he did. That's, that's, that's it and, and, and, when we pick that trash up, when we pick that trash up we should make a sign that says "No, you cannot come inside, you have to stay like this until we get all that trash picked up and then you can ride on it and and we can make some signs that said "Make sure do not (inaudible) trash, trash...

Make sure what sorry?

U3: ...not throw trash (inaudible)

Make sure to not throw trash.

U3: ...on the ground or else you, else you won't go in this highway ever again! That's what I think.

Okay, do you want to move on to the drawing now?

U3: Yeah.

Okay...

U3: (inaudible)

One more thing?

U3: Is... when I never leave markers out because they could get dry.....

\section{Transcript for U4}

Okay today is July $27^{\text {th }}$ with U4. Okay. Do you know what the environment is?

U4: Yeah

Yeah? Can you tell me about it?

U4: I know how to help the environment to make it illegal to throw stuff on the ground and into the ocean, and we can pick up anything we see on the ground to make less pollution.

Okay, what does picking up garbage and making it illegal for...

U4: And put it in the recycle bins and garbages and you can also tell people about it.

Tell people about what?

U4: The environment.

What would you tell them about the environment?

U4: I would tell them about gummy bears and stuff on the ground.

What about the gummy bears on the ground?

U4: It can make it pollute, it can get dirty and somebody can step on it and that makes pollution and pollution makes the environment die and...

It makes, sorry can you say that again?

U4: It makes the environment die.

Die, yes...and if the environment dies, what will happen?

U4: There will be less oxygen. We wouldn't have any oxygen left for us. 
Is there anything else that will happen if we, if the environment dies?

U4: N. O.

Pardon?

U4: N.O.

Oh okay, um... hum...what sorts of things do you like about the environment?

U4: (signing) I'm a little gummy bear lalalalala ... I'm a little gummy bear, gummy bear!

Is that what you like about the environment, gummy bears?

U4: Yeah...I mean don't like gummy bears about the environment, I like um... all the trees and the apples
and everything (inaudible)

Sorry you said the trees and apples, what did you say after that?

U4: That brings us, that the environment brings us. (Signing) I'm a little gummy bear...(makes noises with his mouth)

So you like the things that the environment brings us?

U4: (Inaudible). (Signing) I'm a little gummy bear; I'm a little gummy bear (makes noises with his mouth).

Is there anything else you like about the environment?

U4: N.O.

No? Do you want to tell me what sorts of things you don't like about the environment?

U4: Yep

What sorts of things that you don't like?

U4: I don't like apples falling on my head.

What other things do you not like about the environment?

U4: I don't like it because when the grass gets wet I, I slip on it.

So you don't like wet grass?

U4: No

When you slip...

U4: Yeah...what that over there?

Mother: It's Gabriella hunny...It's okay... did you say that to help the environment I thought I heard you say...did you say gummy bears or the government?

U4: The government...

The government...?

U4: Mmmmmm gummy bears!

Mother: I think he was talking about gummy bears.

Okay, is there anything else that you don't like about the environment? I know you said you don't like apples falling on your head, and you don't like it when you slip on the wet grass....are there other things you don't like?

U4: I don't like the taste of grass or leaves.

Taste of grass or leaves... I don't think that they taste very good either...

U4: I've swallowed them...

Really? I bet you don't want to do that again... 
U4: Yep

No...

U4: a ladybug landed on it...

Really? Did you eat the ladybug too?

U4: No

Oh that's good, that would be crunchy...haha. Is there anything else that you like or you don't like about the environment that you want me to put down here?

U4: I don't like the bark of the trees because, I doesn't taste very good...

I bet you that animals that eat bark and things on the bark, they probably think it's tasty.

U4: Yeah!

Yeah

U4: (inaudible)...bugs I ate, that was good...

Hahahaha! Is there anything else you want to tell me that you like or you don't like?

U4: (Shakes his head)

No? Okay

Mother: (inaudible) hahahaha...Tell me to leave if I have to.

U4: (inaudible)

(inaudible)

Mother: What else is part of the environment (child's name)?

U4: Birds

Birds, yeah

U4: Chinchillas, monkeys, and hamsters, guinea pigs, (inaudible) and don't forget scorpions...

Scorpions...

U4: And then tarantulas

Chinchillas...

U4: Not chinchillas, tarantulas!

Tarantulas...

U4: I said tarantula (inaudible)... and gummy bears.

And gummy bears, we will never forget the gummy bears.

U4: hahahaha...

Okay...

U4: And us!

And us, of course people right? Lots of people in the world, in the environment. Okay...Do you know if there's anything we can do to help the environment? What sorts of things can we do to help?

U4: I already said that!

You want to tell me again?

U4: Just listen to the tape! 
Okay, we can listen to the tape...Do you think that...I know...okay... What you said about what we can do, you said that we can make it illegal to throw things on the ground right? You said that we can pick up trash and put it in the recycling bins or in the trash when it's supposed to go there. You can tell people about the environment and how pollution makes the earth die, right? And how if the environment dies, we will have less oxygen, right? Is that what you said?

U4: And less gummy bears...

Less gummy bears on the ground right, is what you said?

U4: Yeah, no gummy bears on the ground...

Now, do you think that, as a kid that you can do all of these things to help the environment?

U4: (Nods head to indicate yes)

Yeah? How are you going to do that?

U4: Ask her (points to his mother)

I'm not asking her, I'm asking you! So my project it's important, I want to know what kids think, not what Moms think, otherwise I would be talking to your Mom.

U4: Um...I think we can um...help the trees and plants to survive.

How would be help the trees and plants to survive?

U4: Water them, give then lots of sunlight...give them a good life and home....

Okay...

U4: And not kill them.

Not kill them?

U4: Not cut them down or anything...

Un hun...

U4: And that's all I want to say for now.

Okay, you all done then?

U4: (Nods to indicate yes)

Thank you

U4: Thank you 



\section{References:}

Adelman, L.M., Falk, J.H., \& James, S. (2000). Impact of National Aquarium in Baltimore on visitor's conservation attitudes, behaviors, and knowledge. Curator, 43(1), 33-61.

advocacy. (n.d.). Merriam-Webster's Dictionary of Law. Retrieved August 24, 2007, from Dictionary.com website: http://dictionary.reference.com/browse/advocacy

Ballantyne, R., \& Bain, J. (1995). Enhancing environmental conceptions: An evaluation of cognitive conflict and structured controversy learning units. Studies in Higher Education, 20(3), 293-303.

Ballantyne, R., Connell, S., \& Fien, J. (1998). Students as catalysts of environmental change: A framework for researching intergenerational influence through environmental education. Environmental Education Research, 4(3), 285-298.

Barclay-McLaughlin, G. \& Hatch, J. A. (2005). Studying across race: A conversation about the place of difference in qualitative research. Contemporary Issues in Early Childhood, 6(3), 216-232.

Barraza, L., \& Walford, R. A. (2002). Environmental education: A comparison between English and Mexican school children. Environmental Education Research, 8(2), 171-186.

Bixler, R. D., Floyd, M. F. \& Hammitt, W. E. (2002). Environmental socialization: Quantitative tests of the childhood play hypothesis. Environment and Behavior, 34(6), 795-818.

Berenguer, J. (2007). The effects of empathy in proenvironmental attitudes and behaviors. Environment and Behavior, 39(2), 269-283.

Chawla, L. (2006). Research methods to investigate significant life experiences: Review and recommendations. Environmental Education Research, 12(3-4), 359-374.

Cohen, S., (1994). Children and the environment: Aesthetic learning (for parents particularly. Childhood education, 70(5), 302-305.

Cohen, S. \& Horm-Wingerd, D. (1993). Children and the environment: Ecological awareness among preschool children. Environment and Behavior, 25(1), 103-120.

Costarelli, S., \& Coslloca, P. (2004). The effects of attitudinal ambivalence on proenvironmental behavioural intentions. Journal of Environmental Psychology, 24, 279-288. 
Cresswell, J. W. (2005). Educational research. Planning conducting and evaluated quantitative and qualitative research. Upper Saddle River, N.J.: Pearson Merrill Prentice Hall.

Daniel, T.C. (1990). Measuring the quality of the natural environment: A psychological approach. American Psychologist, 45(5), 633-637.

Eagles, P., \& Demare, R., (1999). Factors influencing children's environmental attitudes. Journal of Environmental Education, 30(4), 33-40.

Evens, G. W. (2006). Child development and the physical environment. Annual Review of Psychology. 57, 423-451.

Falkheimer, J. \& Heide, M. (2006). Multicultural crisis communication: Towards a social-constructionist perspective. Journal of Contingencies and Crisis Management. 14(4), 180-189.

Fisman, L. (2005). The effects of local learning on environmental awareness in children: An empirical investigation. Journal of Environmental Education, 36(3), 39-50.

Folsom, J, Hunt, C., Cavicchio, M., Schoenemann, A., \& D'Amato, M. (2007). How do you know that? Science and Children, 44(5), 20-25.

Frantz, C., Mayer, S., Norton, C., \& Rock, M. (2005). There is no "I" in nature: The influence of self-awareness on connectedness to nature. Journal of Environmental Psychology, 25, 427-436.

Hillcoat, J., Forge, K., Fien, J., \& Baker, E. (1995). 'I think it's really great that someone is listening to us...': Young people and the environment. Environmental Education Research, 1(2), 159-171.

Howe, D. C., Kahn, P. H., Jr. \& Friedman, B. (1996) Along the Rio Negro: Brazilian children's environmental views and values. Developmental Psychology, 32(6), 979-987.

Hyun, E. (2005). How is young children's intellectual culture of perceiving nature different from adults'? Environmental Education Research, 11(2), 199-214.

Kahn P.H. Jr. (April 2001) Structural-Development Theory and children's experience of nature. Paper presented at the Biennial Meeting of the Society for Research in child Development, Minneapolis Minnesota.2-18.

Kahn, P. H., Jr., \& Friedman, B. (1995). Environmental views and values of children in an inner city black community. Child Development, 66(5), 1403-1417. 
Kahn, P. H. Jr., \& Lourenco, O. (2002). Water, air, fire and earth: A developmental study in Portugal of environmental moral reasoning. Environment and Behavior, 34(4), 405-430.

Kearny, A. R. (2006). Residential development patterns and neighborhood satisfaction: Impacts of density and nearby nature. Environment and Behavior, 38(1), 112-139.

Knussen, C., Yule, F., MacKensie, J, \& Wells, M. (2004). An analysis of intention to recycle household waste: The roles of past behavior, perceived habit, and perceived lack of facilities. Journal of Environmental Psychology, 24, 237-246.

Korhonen, K., \& Lappalainen, A. (2004). Examining the environmental awareness of children and adolescents in the Ranomafana region, Madagascar. Environmental Education Research, 10(2), 195-216.

Kruse, C.K., Card, J.A., (2004). Effects of a conservation education camp program on campers' self-reported knowledge, attitude, and behavior. The Journal of Environmental Education, 35(4), 33-45.

Kyle, G., Graefe, A., Manning, R., \& Bacon, J. (2004). Effects of place attachment on users' perception of social and environmental conditions in a natural setting. Journal of Environmental Psychology, 24, 213-225.

Kyle, G., Mowen, A.J., \& Tarrent, M. (2004). Linking place preferences with place meaning: An examination of the relationship between place motivation and place attachment. Journal of Environmental Psychology, 24, 439-454.

Lewicka, M. (2005). Ways to make people active: The role of place attachment, cultural capital, and neighbourhood ties. Journal of Environmental Psychology, 25, 381395.

Lindenmann-Matthies, P. (2002). The influence of an educational program on children's perception of biodiversity. The Journal of Environmental Education, 33(2), 22-31.

Lindemann_Matthies, P. (2005). 'Loveable' mammals and 'lifeless' plants: How children's interest in common local organisms can be enhanced through observation of nature. International Journal of Science Education, 27(6), 655677.

Littledyke, M. (2004). Primary children's views on science and environmental issues: Examples of environmental cognitive and moral development. Environmental Education Research, 10(2), 217-235.

Mayer, F.S., \& Frantz, C.M. (2004). The Connectedness to Nature Scale: A measure of individuals' feeling in community with nature. Journal of Environmental Psychology, 24, 515-530. 
Meinhold, J. L., \& Malkus, A. J. (2005). Adolescent environmental behaviours: can knowledge, attitudes, and self-efficacy make a difference? Environment and Behavior, 37(4), 511-532.

Milfont, T. L., \& Gouveia, V. V. (2006). Time perspective and values: An exploratory study of their relations to environmental attitudes. Journal of Environmental Psychology, 26, 72-82.

Miller, D. (1997). One strategy for assessing the trustworthiness of qualitative research: Operationalilzing the external audit. Paper presented at the Annual Meeting of the American Educational Research Association. (Chicago, IL, March 24-28, 1997), $1-50$.

Moore, G.T. (1985). The designed environment and cognitive development: A brief review of five domains of research. Children's Environments Quarterly, 2, 26-33.

Morrow, S.L. (2005). Quality and trustworthiness in qualitative research in counseling psychology. Journal of Counseling Psychology, 52(2), 250-260.

Myers O. E. Jr., Saunders, C.D., \& Garrett, E. (2004). What do children think animals need? Developmental trends. Environmental Education Research, 10(4), 545-562.

Nairn, K., Panelli, R., \& McCormack, J. (2003) Destabilizing dualisms: Young people's experiences of rural an Durban environments. Childhood, 10(1), 9-42.

natural. (n.d.). The American Heritage ${ }^{\circledR}$ Dictionary of the English Language, Fourth Edition. Retrieved August 24, 2007, from Dictionary.com website: http://dictionary.reference.com/browse/natural

Olofsson, A., \& Öhman, S. (2006). General beliefs and environmental concern: Transatlantic comparisons. Environment and Behavior, 38(6), 768-790.

Palmer, J.A., Suggate, J., Robottom, I., \& Hart, P. (1999). Significant life experiences and formative influences on the developmental awareness in the UK, Australia and Canada. Environmental Education Research, 5(2), 181-200.

Pringle, R., Hakverdi, M., Cronin-Jones, L., \& Johnson, C. (2003). Zoo school for preschoolers: Laying the foundation for environmental education. Annual Meeting of the American Education Research Association, 22p.

responsible. (n.d.). The American Heritage ${ }^{\circledR}$ Dictionary of the English Language, Fourth Edition. Retrieved August 24, 2007, from Dictionary.com website: http://dictionary.reference.com/browse/responsible 
Rogan, R., O'Connor, \& Horwitz, P. (2005). Nowhere to hide: awareness and perceptions of environmental change, and their influence on relationships with place. Journal of Environmental Psychology, 25, 147-158.

rural. (n.d.). The New Lexicon Webster's Encyclopedic Dictionary of the English Language, Canadian Edition. USA, Lexicon Publications, INC.

Smith, R.W. \& Bugni, V. (2006). Symbolic Interaction Theory and architecture. Symbolic Interaction, 29(2), 123-155.

UNEP (2007) United Nations Environmental Program Resource Kit. Available online at: http://www.unep.org/tools/ (accessed 10 Sept 2007).

UNFCCC (2005) United Nations Framework Convention on Climate Change. Available online at: http://unfccc.int/kyoto protocol/items/2830.php (accessed $10 \mathrm{Sept}$ 2007).

urban. (n.d.). The New Lexicon Webster's Encyclopedic Dictionary of the English Language, Canadian Edition. USA, Lexicon Publications, INC.

Van Liere, K.D., \& Dunlap, R.E. (1980). The social basis of environmental concern: A review of hypotheses, explanations and empirical evidence. Public Opinion Quarterly, 181-197.

Van Velsor, S. W. \& Nilson, C.H. (2006). A qualitative investigation of the urbanAfrican-American and Latino adolescent experience with wildlife. Human Dimensions of Wildlife, 11, 359-370.

Vaughan, C., Gack, J., Solorazano, H., \& Ray, R. (2003). The effect of environmental education on schoolchildren, their parents, and community members: A study of intergenerational and intercommunity learning. The Journal of Environmental Education, 34(3), 12-21. 
$30-75=20$ 